\title{
Pore-size expansion of hexagonal-structured nanocrystalline titania/CTAB Nanoskeleton using cosolvent organic molecules
}

Toshio Sakai, ${ }^{1 *}$ Hanae Yano, ${ }^{2}$ Hirobumi Shibata, ${ }^{3}$ Takeshi Endo, ${ }^{4}$ Kazutami Sakamoto, ${ }^{2}$ Hiroshi Fukui, ${ }^{5}$ Naokiyo Koshikawa, ${ }^{6}$ Hideki Sakai, ${ }^{2,4}$ Masahiko Abe ${ }^{2,4}$

${ }^{1}$ International Young Researchers Empowerment Center, Shinshu University, 4-17-1 Wakasato, Nagano 380-8553, Japan

${ }^{2}$ Department of Pure and Applied Chemistry, Faculty of Science and Technology, Tokyo University of Science, 2641 Yamazaki, Noda, Chiba 278-8510, Japan.

${ }^{3}$ Department of Life and Environmental Sciences, Faculty of Engineering, Chiba Institute of Technology, 2-17-1 Tsudanuma, Narashino, Chiba, 275-0016, Japan.

${ }^{4}$ Research Institute for Science and Technology, Tokyo University of Science, Noda, Chiba 278-8510, Japan.

${ }^{5}$ FUKUI Engineering Consulting Office, 18-20 Fujimigaoka, Tsuduki-ku, Yokohama, Kanagawa 224-0051, Japan.

${ }^{6}$ Japan Aerospace Exploration Agency (JAXA), 2-1-1 Tsukuba, Ibaraki 305-8505, Japan

* To whom correspondence should be addressed.

phone : $+81-26-269-5405$

fax : $+81-26-269-5424$

e-mail : tsakai@shinshu-u.ac.jp 


\section{Abstract}

Pore-size expansion of hexagonal-structured assembly of nanocrystalline titania (anatase) combined with cetyltrimethyammonium bromide $\left(\mathrm{CH}_{3}\left(\mathrm{CH}_{2}\right)_{15} \mathrm{~N}^{+}\left(\mathrm{CH}_{3}\right)_{3} \mathrm{Br}\right.$, $\left.\mathrm{CTAB}\right)$ (named as $\mathrm{Hex}-\mathrm{ncTiO}_{2} / \mathrm{CTAB}$ Nanoskeleton) was achieved with the aid of cosolvent organic molecules (COMs). The pore-size expanded $\mathrm{Hex}-\mathrm{ncTiO}_{2} / \mathrm{CTAB}$ Nanoskeleton was prepared through the sol-gel reaction of titanium oxysulfate sulfuric acid hydrate $\left(\mathrm{TiOSO}_{4} \cdot \mathrm{xH}_{2} \mathrm{SO}_{4} \cdot \mathrm{xH}_{2} \mathrm{O}\right.$, TiOSAH) in an aqueous solution initiated by CTAB swollen micelles pre-prepared with the addition of COMs into aqueous CTAB micellar solutions at 60 ${ }^{\circ} \mathrm{C}$ (the product was named as $\mathrm{Hex}-\mathrm{ncTiO}_{2} / \mathrm{CTAB} / \mathrm{COM}$ Nanoskeleton). Long-chain alcohol (1-hexadecanol, $\mathrm{C} 16 \mathrm{OH})$, normal alkane (n-decane, C10) and benzene derivatives (benzene, Bz; 1,3,5-trimethylbenzene, TMB; 1,3,5-triethylbenzene, TEB; 1,3,5-triisopropylbenzene, TiPB) were used as COMs to evaluate the effects of COM solubilization site in CTAB micelles and COM molecular size on the pore-size expansion of the Hex-ncTiO $2 / \mathrm{CTAB} / \mathrm{COM}$ Nanoskeleton. We found that 1,3,5-trimethylbenzene (TMB) and 1,3,5-triethylbenzene (TEB) act as effective COMs for pore-size expansion of the Hex-ncTiO 2 /CTAB/COM Nanoskeleton in aqueous media. Pore sizes (average diameters) of the Hex-ncTiO $2 / \mathrm{CTAB} / \mathrm{TMB}$ Nanoskeleton and $\mathrm{Hex}-\mathrm{ncTiO}_{2} / \mathrm{CTAB} / \mathrm{TEB}$ Nanoskeleton weres enlarged up to $4.2 \mathrm{~nm}$ and $4.3 \mathrm{~nm}$, respectively, while pore size (average diameter) of the Hex-ncTiO $2 /$ CTAB Nanoskeleton prepared in the absence of any COMs was $2.9 \mathrm{~nm}$. We also revealed that thermal stability of the Hex-ncTiO $2 / \mathrm{CTAB} / \mathrm{TMB}$ Nanoskeleton became higher than that of $\mathrm{Hex}-\mathrm{ncTiO} / \mathrm{CTAB}$ Nanoskeleton. The hexagonally pore-structure of the Hex-ncTiO $2 / \mathrm{CTAB} / \mathrm{TMB}$ Nanoskeleton was retained up to $400{ }^{\circ} \mathrm{C}$, while the hexagonally pore-structure of the $\mathrm{Hex}-\mathrm{ncTiO} / \mathrm{CTAB}$ Nanoskeleton was kept up to $300{ }^{\circ} \mathrm{C}$.

Keywords: Hexagonal-structured assembly, Nanocrystalline titania, Nanoskeleton, Pore-size expansion, Cosolvent organic molecule 


\section{Introduction}

Mesostructured crystalline (anatase) titania $\left(\mathrm{TiO}_{2}\right)$ with large pores has attracted significant attention because of their potential applications such as large molecule separation, catalysis, medical implants, shape-selective heterojunctions and dye-sensitized solar cell.[1-22] Therefore, the development of simple and versatile methods for the fabrication of large pore-sized mesostructured crystalline titania is an important and challenging task. [1-22] However, compared with the mesostructured silica materials such as MCM-41 materials prepared with cetyltrimethyammonium bromide $\left(\mathrm{CH}_{3}\left(\mathrm{CH}_{2}\right)_{15} \mathrm{~N}^{+}\left(\mathrm{CH}_{3}\right)_{3} \mathrm{Br}^{-}, \mathrm{CTAB}\right)$ and poly(ethylene oxide)-poly(propylene oxide)-poly(ethylene oxide) block copolymers,[23-29] the fabrication of large pore-sized mesostructured crystalline titania is still a big challenge because mesostructure of titania materials generally collapses during the crystallization by calcination.[10-22] In addition, preparation of mesostructured crystalline titania typically requires alcohol-based solvents,[10-22] so the replacement of many conventional alcohols as solvents used in the sol-gel reaction to the environmental benign alternatives is also an important challenge toward achieving the goal of green chemical processing.

Then, we considered to apply a preparation method that we have recently developed[30-33] to the fabrication of larger pore-sized mesostructured crystalline titania. Our synthetic method enables to produce the hexagonal-structured assembly of nanocrystalline titania (anatase) combined with cetyltrimethyammonium bromide $\left(\mathrm{CH}_{3}\left(\mathrm{CH}_{2}\right)_{15} \mathrm{~N}^{+}\left(\mathrm{CH}_{3}\right)_{3} \mathrm{Br}^{-}, \mathrm{CTAB}\right)$ (named as Hex-ncTiO $2 / \mathrm{CTAB}$ Nanoskeleton) through the sol-gel reaction of titanium oxysulfate sulfuric acid hydrate $\left(\mathrm{TiOSO}_{4} \cdot \mathrm{xH}_{2} \mathrm{SO}_{4} \cdot \mathrm{xH}_{2} \mathrm{O}\right.$, TiOSAH) in an aqueous solution, which is initiated by CTAB spherical micelles in the absence of any other additives such as base and acid.[30-33] Compared with the reported methods,[10-21] our synthetic system involves benefits, for example, spontaneous formation of hexagonal structure and crystallization of titania (anatase formation) in aqueous solutions 
under mild conditions (e.g., at $60{ }^{\circ} \mathrm{C}$ for $24 \mathrm{~h}$ ) through the simple procedure (mixing of aqueous solutions containing TiOSAH and CTAB but no other additives such as base and acid as reaction initiators required, and no evaporation and calcination processes required) and water as a solvent.[30-33] This matches with recent emerging environmental requirements on nanomaterial synthetic strategy such as utilization of environmentally benign solvents, a simplified procedure, minimized material use and low energy input. Therefore, the fabrication of larger pore-sized $\mathrm{Hex}-\mathrm{ncTiO}_{2} / \mathrm{CTAB}$ Nanoskeleton should provide further opportunities for the applications of mesostructured titania materials.

In this paper, we report the fabrication of larger pore-sized $\mathrm{Hex}-\mathrm{ncTiO}_{2} / \mathrm{CTAB}$ Nanoskeleton using CTAB swollen micelles (that were prepared with the addition of cosolvent organic molecules (COMs) into aqueous CTAB micellar solutions) as templates and structure-directing agents (the product was named as $\mathrm{Hex}-\mathrm{ncTiO}_{2} / \mathrm{CTAB} / \mathrm{COM}$ Nanoskeleton) (see Figure 1). In particular, long-chain alcohol (1-hexadecanol, C16OH), normal alkane ( $n$-decane, C10), benzene derivatives (benzene, Bz; 1,3,5-trimethylbenzene, TMB; 1,3,5-triethylbenzene, TEB; 1,3,5-triisopropylbenzene, TiPB) were selected as COMs to investigate the effects of solubilization site of COMs in CTAB micelles and molecular size of $\mathrm{COM}$ on the pore-size expansion of the $\mathrm{Hex}-\mathrm{ncTiO}_{2} / \mathrm{CTAB} / \mathrm{COM}$ Nanoskeleton.

\section{Experimental}

\subsection{Preparation of $\mathrm{Hex}-\mathrm{ncTiO}{ }_{2} / \mathrm{CTAB}$ Nanoskeleton}

Hex-ncTiO 2 CTAB Nanoskeleton was prepared through the aging (sol-gel reaction) at $60{ }^{\circ} \mathrm{C}$ for $24 \mathrm{~h}$ after mixing of aqueous solutions $(18.2 \mathrm{~m} \Omega \mathrm{cm}$, Millipore-filtered water) containing $3.0 \mathrm{~mol} \mathrm{~L}^{-1}$ titanium oxysulfate sulfuric acid hydrate $\left(\mathrm{TiOSO}_{4} \cdot \mathrm{xH}_{2} \mathrm{SO}_{4} \cdot \mathrm{xH}_{2} \mathrm{O}\right.$; TiOSAH, Aldrich) and $60 \times 10^{-3} \mathrm{~mol} \mathrm{~L}^{-1}$ cetyltrimethylammonium bromide $\left(\mathrm{CH}_{3}\left(\mathrm{CH}_{2}\right)_{15} \mathrm{~N}^{+}\left(\mathrm{CH}_{3}\right)_{3} \mathrm{Br}^{-}\right.$; CTAB, Aldrich) (following the procedure that we reported 
previously).[30-33] The precipitate produced was filtrated and washed by water, and finally, powder of the $\mathrm{Hex}-\mathrm{ncTiO} / \mathrm{CTAB}$ Nanoskeleton was obtained after drying at $120{ }^{\circ} \mathrm{C}$ for $10 \mathrm{~h}$ under air atmosphere.

\subsection{Preparation of $\mathrm{Hex}_{-n c T i O} / \mathrm{CTAB} / \mathrm{COM}$ Nanoskeleton}

Hex-ncTiO $2 / \mathrm{CTAB} / \mathrm{COM}$ Nanoskeleton was prepared by mixing of a $3.0 \mathrm{~mol} \mathrm{~L}^{-1}$ TiOSAH aqueous solution with the pre-prepared aqueous CTAB swollen miceller solutions at $60{ }^{\circ} \mathrm{C}$, and reacting at the same temperature for $24 \mathrm{~h}$. The swollen CTAB micelles were prepared by mixing of a cosolvent organic molecule $(\mathrm{COM})$ with a $60 \times 10^{-3} \mathrm{~mol} \mathrm{~L}^{-1} \mathrm{CTAB}$ aqueous solutions in the range of 0-28 mixing ratio $\left(r_{\mathrm{COM}}=\mathrm{COM} / \mathrm{CTAB}\right.$ molar ratio $)$ at 60 ${ }^{\circ} \mathrm{C}$ for $24 \mathrm{~h}$. We selected 1-hexadecanol $\left(\mathrm{CH}_{3}\left(\mathrm{CH}_{2}\right)_{15} \mathrm{OH}\right.$; C16OH, Tokyo Chemical Industry Co., Ltd.), n-decane $\left(\mathrm{CH}_{3}\left(\mathrm{CH}_{2}\right)_{8} \mathrm{CH}_{3} ; \mathrm{C} 10\right.$, Wako Pure Chemical Industries, Ltd.) and 1,3,5-trimethylbenzene $\left(\left(\mathrm{CH}_{3}\right)_{3} \mathrm{C}_{6} \mathrm{H}_{3} ; \mathrm{TMB}\right.$, Tokyo Chemical Industry Co., Ltd.) as COMs to evaluate the connection between solubilization site of COM in a CTAB micelle and pore size of the $\mathrm{Hex}-\mathrm{ncTiO} / \mathrm{CTAB} / \mathrm{COM}$ Nanoskeleton formed, because 1-hexadecanol $(\mathrm{C} 16 \mathrm{OH})$ molecules are solubilized between surfactant molecules, $n$-decane $(\mathrm{C} 10)$ molecules are solubilized in the micelle core, and 1,3,5-trimethylbenzene (TMB) molecules are solubilized in both micelle core and the vicinity of micelle surface (hydrophilic cationic region) due to an interaction between $\pi$-electron of TMB and cationic group of CTAB.[23-28, 34, 35] We also used benzene $\left(\mathrm{C}_{6} \mathrm{H}_{6} ; \mathrm{Bz}\right.$, Tokyo Chemical Industry Co., Ltd.), 1,3,5-triethylbenzene $\left(\left(\mathrm{C}_{2} \mathrm{H}_{5}\right)_{3} \mathrm{C}_{6} \mathrm{H}_{3} ;\right.$ TEB, Tokyo Chemical Industry Co., Ltd. $)$ and 1,3,5-triisopropylbenzene $\left(\left(\mathrm{C}_{3} \mathrm{H}_{7}\right)_{3} \mathrm{C}_{6} \mathrm{H}_{3}\right.$; TiPB, Tokyo Chemical Industry Co., Ltd. $)$ as COMs to examine the relationship between molecular size of COM solubilized in CTAB micelles and pore size of the $\mathrm{Hex}_{-\mathrm{ncTiO}} / \mathrm{CTAB} / \mathrm{COM}$ Nanoskeleton formed. Hex-ncTiO $2 / \mathrm{CTAB} / \mathrm{COM}$ Nanoskeleton powder was finally obtained after same procedure with $\mathrm{Hex}-\mathrm{ncTiO} / \mathrm{CTAB}$ Nanoskeleton powder (see section 2.1). 


\subsection{Characterization}

Mesostructure, crystal type and crystallinity of the Hex-ncTiO $/$ CTAB Nanoskeleton and Hex-ncTiO $2 / \mathrm{CTAB} / \mathrm{COM}$ Nanoskeleton thus prepared were characterized using powder X-ray diffraction (XRD) (X'pert-MPD $\mathrm{CuK} \alpha$ radiation, Philips). Mesostructure, pore size (diameter) and framework thickness of the Hex-ncTiO $/$ CTAB Nanoskeleton and $\mathrm{Hex}-\mathrm{ncTiO}_{2} / \mathrm{CTAB} / \mathrm{COM}$ Nanoskeleton were confirmed by combination of values of $d_{100}$-spacing (distance between pores $=$ pore diameter + framework thickness) estimated from the position of the XRD peak assigned to (100) facet by Bragg's equation[36] and the direct observation using transmission electron microscopy (TEM) (H-7650, Hitachi High Technology, $120 \mathrm{kV}, 3,0 \mu \mathrm{A})$.

\subsection{Thermal stability of the Hex-ncTiO $/$ CTAB Nanoskeleton and}

\section{$\mathrm{Hex}_{-\mathrm{ncTiO}} / \mathrm{CTAB} / \mathrm{COM}$ Nanoskeleton}

To assess the thermal stability of the Hex-ncTiO $2 /$ CTAB Nanoskeleton and Hex-ncTiO $2 / \mathrm{CTAB} / \mathrm{COM}$ Nanoskeleton, the Hex-ncTiO ${ }_{2} / \mathrm{CTAB}$ Nanoskeleton and Hex-ncTiO $2 / \mathrm{CTAB} / \mathrm{COM}$ Nanoskeleton were calcined in air atmosphere at various end-temperatures in the range of $150-450{ }^{\circ} \mathrm{C}$. Each sample was calcined with a heating rate of $1{ }^{\circ} \mathrm{C} \mathrm{min}{ }^{-1}$ starting from $25{ }^{\circ} \mathrm{C}$ and kept at the end-temperature for $2 \mathrm{~h}$. Following cooling down of the calcined samples to $25{ }^{\circ} \mathrm{C}, \mathrm{XRD}$ of the calcined samples was measured to confirm the pore structure and crystal growth of the Hex-ncTiO $2 / \mathrm{CTAB}$ Nanoskeleton and Hex-ncTiO $2 / \mathrm{CTAB} / \mathrm{COM}$ Nanoskeleton. The end-temperature was each time increased with $50{ }^{\circ} \mathrm{C}$ for each sample (see Figure 2).

The thermal behavior of the Hex-ncTiO ${ }_{2} / \mathrm{CTAB}$ Nanoskeleton and $\mathrm{Hex}_{-\mathrm{ncTiO}} / \mathrm{CTAB} / \mathrm{COM}$ Nanoskeleton was examined using the thermo gravimetry (TG) and differential scanning calorimetry (DSC) (STA 449C/3/G Jupiter, NETZSCH). Samples were 
heated at a heating rate of $3{ }^{\circ} \mathrm{C} \mathrm{min}-1$ under a nitrogen atmosphere (flow rate of $40 \mathrm{~cm}^{3}$ $\left.\min ^{-1}\right)$.

\section{Results and Discussion}

\subsection{Hex-ncTiO $/$ CTAB Nanoskeleton}

Let us first recall the hexagonal-structured assembly of nanocrystalline titania (anatase) combined with $\mathrm{CTAB}$ (named as $\mathrm{Hex}-\mathrm{ncTiO}_{2} / \mathrm{CTAB}$ Nanoskeleton) that we have developed.[30-33] The Hex-ncTiO $2 /$ CTAB Nanoskeleton was prepared through the sol-gel reaction of TiOSAH with CTAB spherical micelles in an aqueous solution at $60{ }^{\circ} \mathrm{C}$ for $24 \mathrm{~h}$. The formation process is as follows: hexagonal-structured assembly of hydrated titania (amorphous titania) formes immediately after mixing of TiOSAH and CTAB micellar aqueous solutions, and then the hydrated titania transforms into crystalline titania (anatase) through polycondensation with elapsed time at $60{ }^{\circ} \mathrm{C}$ for $24 \mathrm{~h}$ (details have been described in ref. [32]). In a XRD pattern of the Hex-ncTiO $2 / \mathrm{CTAB}$ Nanoskeleton thus formed, noticeable three peaks assigned to hexagonally ordered structure $\left(d_{100}: d_{110}: d_{200}=1: 1 / \sqrt{3}: 1 / 2\right)$ [32] were observed in low-angle region (see upper panel of Figure 3). Also shown in Figure 3 (see bottom panel) was a XRD pattern of the $\mathrm{Hex}-\mathrm{ncTiO}_{2} / \mathrm{CTAB}$ Nanoskeleton observed in wide-angle region, which was assigned to crystalline titania ((101) and (200) facets of anatase).[36, 37] Additionally, honeycomb-like structure with the pore diameter of $2.9 \mathrm{~nm}$ (average diameter) and framework (wall) thickness of $1.2 \mathrm{~nm}$ (average thickness) (see upper image of Figure 4) and long-range lined structure (see bottom image of Figure 4) of the Hex-ncTiO $2 / \mathrm{CTAB}$ Nanoskeleton were observed by TEM. Sum of the pore diameter and framework thickness was in good agreement with the value of $d_{100}$-spacing $(4.1 \mathrm{~nm})$ (distance between pores $=$ pore diameter + framework thickness) estimated from the (100) peak of low-angle XRD (see Table 1). 
In order to evaluate the mechanism on the hydrolysis reaction of TiOSAH initiated by CTAB and formation of hexagonal-structured assembly mediated by CTAB, we have tested various surfactants such as alkyltrimethylammonium bromides $\left(\mathrm{CH}_{3}\left(\mathrm{CH}_{2}\right)_{n-1} \mathrm{~N}^{+}\left(\mathrm{CH}_{3}\right)_{3} \mathrm{Br}\right.$; $\mathrm{C}_{n} \mathrm{TAB}, n=12,14,16$ and 18$)$ and sodium dodecyl sulphate $\left(\mathrm{CH}_{3}\left(\mathrm{CH}_{2}\right)_{11} \mathrm{OSO}_{3}{ }^{-} \mathrm{Na}^{+}\right.$; SDS $)$, polyelectrolytes such as poly(allylamine hydrochloride $)\left(\left[\mathrm{CH}_{2} \mathrm{CH}\left(\mathrm{CH}_{2} \mathrm{NH}_{2}\right) \mathrm{HCl}\right]_{n} ; \mathrm{PAH}\right)$ and poly(sodium 4-styrenesulfonate, $\left[\mathrm{C}_{8} \mathrm{H}_{7} \mathrm{SO}_{3} \mathrm{Na}\right]_{n} ;$ PSSS) and formamide $\left(\mathrm{HCONH}_{2}\right)$ in previous work.[32] We have revealed that $\mathrm{C}_{n} \mathrm{TAB}(n=12,14,16$ and 18$)$ mediated the formation of Hex-ncTiO $2 / \mathrm{C}_{n} \mathrm{TAB}$ Nanoskeleton. Poly(allylamine hydrochloride) (PAH) and formamide also initiated the hydrolysis reaction of TiOSAH but did not mediate the formation of hexagonal-structured assembly. On the other hand, anionic system such as SDS and PSSS did not initiate the hydrolysis reaction of TiOSAH and did not produce titania. These findings suggest that nitrogens, amino groups and/or quaternary ammonium ions in the molecules and polymers act as catalysts and/or reactants to initiate the hydrolysis reaction of TiOSAH in aqueous solutions. Moreover, surfactant $\left(\mathrm{C}_{n} \mathrm{TAB}\right)$ micelles are required for the formation of hexagonal-structured assembly.

\subsection{Hex-ncTiO 2 /CTAB/COM Nanoskeleton prepared using 1-hexadecanol (C16OH), n-decane (C10) and 1,3,5-trimethylbenzene (TMB)}

It is reported that 1,3,5-trimethylbenzene (TMB) acts as an appropriate cosolvent organic molecule $(\mathrm{COM})$ for pore-size enlargement of the mesostructured silica materials. [23-28] This is due to the solubilization site of TMB in CTAB micelles (both micelle core and ionic outer layer (hydrophilic cationic region) caused by an interaction between $\pi$-electron of $\mathrm{TMB}$ and cationic group of $\mathrm{CTAB}$ ) and the resulting large amount of TMB solubilizing into CTAB micelles.[23-28] Then, we examined the connection between pore size of $\mathrm{Hex}_{-\mathrm{ncTiO}} / \mathrm{CTAB} / \mathrm{COM}$ Nanoskeleton formed and solubilisation site of $\mathrm{COM}$ in CTAB micelles. In order to evaluate the connection between pore size of 
Hex-ncTiO $2 / \mathrm{CTAB} / \mathrm{COM}$ Nanoskeleton formed and solubilisation site of COMs in CTAB micelles, we used 1-hexadecanol $(\mathrm{C} 16 \mathrm{OH}), n$-decane $(\mathrm{C} 10)$ and 1,3,5-trimethylbenzene (TMB) as COMs because $\mathrm{C} 16 \mathrm{OH}$ molecules are solubilized between CTAB molecules, $\mathrm{C} 10$ molecules are solubilised in hydrophobic micelle core, and TMB molecules are solubilised in both hydrophobic micelle core and ionic outer layer of CTAB micelles.[23-28, 34, 35]

In the utilization of 1-hexadecanol $(\mathrm{C} 16 \mathrm{OH})$ as a $\mathrm{COM}, \mathrm{Hex}-\mathrm{ncTiO}_{2} / \mathrm{CTAB} / \mathrm{C} 16 \mathrm{OH}$ Nanoskeleton was prepared in the $r_{\mathrm{C} 16 \mathrm{OH}}$ range of 0-1 (see Figure 5). Low-angle XRD observed noticeable three peaks corresponding to (100), (110) and (200) facets or a peak corresponding to (100) facet of the hexagonally ordered structure in the $r_{\mathrm{C} 16 \mathrm{OH}}$ range of $0-1$ (see upper panel of Figure 5). Wide-angle XRD patterns also shown in Figure 5 (see bottom panel) indicate that the $\mathrm{Hex}-\mathrm{ncTiO} / 2 / \mathrm{CTAB} / \mathrm{C} 16 \mathrm{OH}$ Nanoskeleton formed is composed of anatase.[36, 37] No noticeable peak was observed in low-angle XRD above $r_{\mathrm{C} 16 \mathrm{OH}}$ of 1 . Pore-size change of the Hex-ncTiO $2 / \mathrm{CTAB} / \mathrm{C} 16 \mathrm{OH}$ Nanoskeleton was discussed in terms of the shift of the peak assigned to (100) facet in low-angle XRD (see upper panel of Figure 5) and the change in the $d_{100}$-spacing (distance between pores) estimated. The peak corresponding to (100) facet of the $\mathrm{Hex}-\mathrm{ncTiO} / \mathrm{CTAB} / \mathrm{C} 16 \mathrm{OH}$ Nanoskeleton was shifted to lower angle with increase of $\mathrm{C} 16 \mathrm{OH}$ content in $\mathrm{CTAB}$ micellar solutions (see upper panel of Figure 5). Namely, $d_{100}$-spacing (distance between pores) of the $\mathrm{Hex}-\mathrm{ncTiO}_{2} / \mathrm{CTAB} / \mathrm{C} 16 \mathrm{OH}$ Nanoskeleton formed increased with increase of $\mathrm{C} 16 \mathrm{OH}$ content in CTAB micellar solutions. Maximum $d_{100}$-spacing of the $\mathrm{Hex}-\mathrm{ncTiO}_{2} / \mathrm{CTAB} / \mathrm{C} 16 \mathrm{OH}$ Nanoskeleton estimated by Bragg's equation was $4.9 \mathrm{~nm}$ at $r_{\mathrm{C} 16 \mathrm{OH}}$ of 1 (see Figure 8).

For $n$-decane $(\mathrm{C} 10)$ as a $\mathrm{COM}$, formation of $\mathrm{Hex}-\mathrm{ncTiO}_{2} / \mathrm{CTAB} / \mathrm{C} 10$ Nanoskeleton was confirmed in the $r_{\mathrm{C} 10}$ range of 0-20 (see Figure 6). Three peaks assigned to (100), (110) and (200) facets of hexagonally ordered structure became broader, and the peak corresponding to $(100)$ facet of the $\mathrm{Hex}-\mathrm{ncTiO} / \mathrm{CTAB} / \mathrm{C} 10$ Nanoskeleton was shifted to lower angle with increase of $\mathrm{C} 10$ content in CTAB micellar aqueous solutions up to $r_{\mathrm{C} 10}$ of 6 (see upper panel of 
Figure 6). Above $r_{\mathrm{C} 10}$ of 6 , position of the peak corresponding to (100) facet of the Hex-ncTiO $2 / \mathrm{CTAB} / \mathrm{C} 10$ Nanoskeleton remained unchanged up to $r_{\mathrm{C} 10}$ of 20 (see upper panel of Figure 6). So maximum $d_{100}$-spacing of the Hex-ncTiO $2 / \mathrm{CTAB} / \mathrm{C} 10$ Nanoskeleton estimated was $5.8 \mathrm{~nm}$ (see Figure 8). Anatase formation of the $\mathrm{Hex}-\mathrm{ncTiO}_{2} / \mathrm{CTAB} / \mathrm{C} 10$ Nanoskeleton was confirmed by wide-angle XRD patterns (see bottom panel of Figure 6).[36, 37]

In the case of 1,3,5-trimethylbenzene (TMB), noticeable three peaks corresponding to (100), (110) and (200) facets or a peak corresponding to (100) facet of the hexagonally ordered structure in $\mathrm{Hex}-\mathrm{ncTiO} / \mathrm{CTAB} / \mathrm{TMB}$ Nanoskeleton were observed in the $r_{\mathrm{TMB}}$ range of 0-20 (see upper panel of Figure 7). Wide-angle XRD patterns also shown in Figure 7 (see bottom panel) confirmed that the $\mathrm{Hex}-\mathrm{ncTiO}_{2} / \mathrm{CTAB} / \mathrm{TMB}$ Nanoskeleton formed consisted of anatase.[36, 37] The three peaks corresponding to (100), (110) and (200) facets of the hexagonally ordered structure observed in Hex-ncTiO $2 / \mathrm{CTAB} / \mathrm{TMB}$ Nanoskeleton became broader with increase of TMB content while the peak position remained unchanged up to $r_{\mathrm{TMB}}$ of 8 (see upper panel of Figure 7). The peak corresponding to (100) facet of the Hex-ncTiO 2 /CTAB/TMB Nanoskeleton was shifted to lower angle with increase of TMB content in $\mathrm{CTAB}$ micellar solutions above $r_{\mathrm{TMB}}$ of 8 , and reached lowest angle at $r_{\mathrm{TMB}}$ of 16 (see upper panel of Figure 7). The $d_{100}$-spacings of the $\mathrm{Hex}-\mathrm{ncTiO}_{2} / \mathrm{CTAB} / \mathrm{TMB}$ Nanoskeleton were also plotted in Figure 8 as a function of TMB/CTAB molar ratio. The maximum $d_{100}$-spacing of the Hex-ncTiO $2 / \mathrm{CTAB} / \mathrm{TMB}$ Nanoskeleton formed was $6.8 \mathrm{~nm}$ at $r_{\mathrm{TMB}}$ of 16 (see Figure 8). TEM observation of the Hex-ncTiO $2 / \mathrm{CTAB} / \mathrm{TMB}$ Nanoskeleton formed at $r_{\mathrm{TMB}}$ of 16 revealed the honeycomb-like structure with the average pore diameter of $4.2 \mathrm{~nm}$ and average framework thickness of $2.7 \mathrm{~nm}$ (see upper image in Figure 9) and long-range lined structure (see bottom image of Figure 9). Sum of the pore diameter (4.2 $\mathrm{nm})$ and framework thickness $(2.7 \mathrm{~nm})$ were consistent with maximum $d_{100}$-spacing $(6.8 \mathrm{~nm})$ 
observed at $r_{\mathrm{TMB}}$ of 16 which corresponds to the distance between pores containing pore diameter and framework thickness (see Table 1).

Let us see again the $d_{100}$-spacings of $\mathrm{Hex}-\mathrm{ncTiO}_{2} / \mathrm{CTAB} / \mathrm{COM}$ Nanoskeleton plotted as a function of $\mathrm{COM} / \mathrm{CTAB}$ molar ratio $\left(r_{\mathrm{COM}}\right)$ summarized in Figure 8. In all COMs, pore sizes of the $\mathrm{Hex}-\mathrm{ncTiO} / 2 / \mathrm{CTAB} / \mathrm{COM}$ Nanoskeleton became larger than that of the Hex-ncTiO 2 /CTAB Nanoskeleton. In particular, TMB worked effectively for the pore-size expansion of Hex-ncTiO $2 / \mathrm{CTAB} / \mathrm{COM}$ Nanoskeleton (see Figure 8). This is most likely related to the size (diamater) of COM-solubilized CTAB swollen micelles depending on the solubilizatin site of COMs in the CTAB micelles. Since 1-hexadecanol (C16OH) molecules are solubilized between surfactant molecules, the size of surfactant micelles typically does not increase significantly.[23-28, 34, 35] On the other hand, $n$-decane (C10) molecules solubilized in the micelle core encourage the size increase of micelles more than C16OH.[23-28, 34, 35] Consequently, the pore size of the $\mathrm{Hex}_{-\mathrm{ncTiO}} / \mathrm{CTAB} / \mathrm{C} 10$ Nanoskeleton would be larger than that of $\mathrm{Hex}-\mathrm{ncTiO}_{2} / \mathrm{CTAB} / \mathrm{C} 16 \mathrm{OH}$ Nanoskeleton. In the case of 1,3,5-trimethylbenzene (TMB) molecules, the size of TMB-solubilized CTAB swollen micelles would be larger than that of C10-solubilized CTAB swollen micelles because TMB molecules are solubilized in both micelle core and the vicinity of micelle surface (hydrophilic cationic region) due to an interaction between $\pi$-electron of TMB and cationic group of CTAB.[23-28, 34, 35] Hence, the pore size of the Hex-ncTiO $/$ CTAB/TMB Nanoskeleton would be larger than that of Hex-ncTiO $2 / \mathrm{CTAB} / \mathrm{C} 10$ Nanoskeleton. We also noticed the broadening and disappearing of the XRD peak corresponding to (100) facet of hexagonally pore-structure with increase of COMs added into CTAB micellar solutions (see Figures 5, 6 and 7), and the resulting limitation of the pore-size $\left(d_{100}\right.$-spacing) expanded in the $\mathrm{Hex}-\mathrm{ncTiO}_{2} / \mathrm{CTAB} / \mathrm{COM}$ Nanoskeleton (see Figure 8). The $d_{100}$-specings of Hex-ncTiO $2 / \mathrm{CTAB} / \mathrm{C} 16 \mathrm{OH}$ Nanoskeleton, Hex-ncTiO $2 / \mathrm{CTAB} / \mathrm{C} 10$ Nanoskeleton and Hex-ncTiO $2 / \mathrm{CTAB} / \mathrm{TMB}$ Nanoskeleton were enlarged up to $4.9 \mathrm{~nm}\left(r_{\mathrm{C} 16 \mathrm{OH}}=1\right), 5.8 \mathrm{~nm}\left(r_{\mathrm{C} 10}\right.$ 
$\geq 6)$ and $6.8 \mathrm{~nm}\left(r_{\mathrm{TMB}}=16\right)$, respectively (see Figure 8). Namely, the addition of excess COMs into $\mathrm{CTAB}$ micellar solutions prevents the formation of $\mathrm{Hex}-\mathrm{ncTiO}_{2} / \mathrm{CTAB} / \mathrm{COM}$ Nanoskeleton. We speculate that the COM-solubilized CTAB swollen micelles would be a main contributor to the formation of $\mathrm{Hex}-\mathrm{ncTiO}_{2} / \mathrm{CTAB} / \mathrm{COM}$ Nanoskeleton while CTAB-stabilized COM-in-water emulsions would be minor. Thus, $\mathrm{Hex}_{-\mathrm{ncTiO}} / \mathrm{CTAB} / \mathrm{COM}$ Nanoskeleton would not be formed at higher content of COM in CTAB micellar solutions because CTAB-stabilized COM-in-water emulsions are a major component in the solution.

\subsection{Thermal stability of $\mathrm{Hex}_{-\mathrm{ncTiO}} / \mathrm{CTAB}$ Nanoskeleton and}

\section{Hex-ncTiO $/$ /CTAB/COMs Nanoskeleton}

We now realized that the addition of COM into aqueous CTAB micellar solutions enabled to expand pore-size of $\mathrm{Hex}-\mathrm{ncTiO}_{2} / \mathrm{CTAB}$ Nanoskeleton. In particular, TMB was the most effective in COMs that we examined for pore-size expansion of the Hex-ncTiO 2 /CTAB Nanoskeleton (see Figure 8). So next, we examined the thermal stability of the Hex-ncTiO $2 /$ CTAB Nanoskeleton and Hex-ncTiO $2 /$ CTAB/COM Nanoskeleton. Typically, the ordered pore-structure of mesostructured titania materials collapses during the calcination due to the crystallization.[10-22]. Therefore, thermal stability of the mesostructured titania materials is one of the important issues to be addressed.

In the case of Hex-ncTiO $/$ CTAB Nanoskeleton, the XRD peak corresponding to (100) facet of hexagonally pore-structure was observed up to $300{ }^{\circ} \mathrm{C}$ while the XRD peak became broader with higher temperature (see Figure 10a). This means that the hexagonally pore-structure of $\mathrm{Hex}-\mathrm{ncTiO} / 2 / \mathrm{CTAB}$ Nanoskeleton remains up to $300{ }^{\circ} \mathrm{C}$. The position of the XRD peak corresponding to (100) facet of hexagonally pore-structure was shifted to higher angle with thermal treatment (see Figure 10a), indicating that the $d_{100}$-spacing (pore size) of the Hex-ncTiO $/$ CTAB Nanoskeleton decreased during heating treatment. Namely, 
Hex-ncTiO 2 /CTAB Nanoskeleton shrank during thermal treatment. The XRD peak corresponding to (100) facet of $\mathrm{Hex}-\mathrm{ncTiO}_{2} / \mathrm{CTAB} / \mathrm{C} 16 \mathrm{OH}$ Nanoskeleton was observed up to $200{ }^{\circ} \mathrm{C}$ with broadening, and the position of the XRD peak corresponding to (100) facet of the hexagonally pore-structure was shifted to higher angle with temperature elevation (see Figure 10b). The shifted peak position was close to that of $\mathrm{Hex}-\mathrm{ncTiO}_{2} / \mathrm{CTAB}$ Nanoskeleton. This indicates that pores shrink during thermal treatment. These findings indicate that thermal stability of the $\mathrm{Hex}-\mathrm{ncTiO}_{2} / \mathrm{CTAB} / \mathrm{C} 16 \mathrm{OH}$ Nanoskeleton was lower than that of $\mathrm{Hex}-\mathrm{ncTiO} 2 / \mathrm{CTAB}$ Nanoskeleton. On the other hand, thermal stability of the Hex-ncTiO $2 /$ CTAB/C10 Nanoskeleton and Hex-ncTiO $2 /$ CTAB/TMB Nanoskeleton became higher than that of Hex-ncTiO $/$ CTAB Nanoskeleton. The XRD peak corresponding to (100) facet of hexagonally pore-structure was observed up to $400{ }^{\circ} \mathrm{C}$ with broadening with temperature elevation in the case of the $\mathrm{Hex}-\mathrm{ncTiO}_{2} / \mathrm{CTAB} / \mathrm{C} 10$ Nanoskeleton and $\mathrm{Hex}_{-\mathrm{ncTiO}} / \mathrm{CTAB} / \mathrm{TMB}$ Nanoskeleton (see Figure 10c $\boldsymbol{\&} \mathbf{d}$ ). No significant shift of the (100) peak position was observed by heating (see Figure 10c \& d). This indicates no significant shrinkage of $\mathrm{Hex}-\mathrm{ncTiO}_{2} / \mathrm{CTAB} / \mathrm{C} 10$ Nanoskeleton and Hex-ncTiO $/$ /CTAB/TMB Nanoskeleton during thermal treatment. The highest temperatures that the XRD peak corresponding to (100) facet of hexagonally structure was observed were summarized in

Table 2.

The different thermal stability between $\mathrm{Hex}-\mathrm{ncTiO} / \mathrm{CTAB}$ Nanoskeleton, Hex-ncTiO $2 /$ CTAB/C16OH Nanoskeleton, Hex-ncTiO $2 /$ CTAB/C10 Nanoskeleton and Hex-ncTiO 2 /CTAB/TMB Nanoskeleton that we observed is most likely attributed to the amount of residual water, $\mathrm{CTAB}$ and $\mathrm{COM}$ in the $\mathrm{Hex}-\mathrm{ncTiO}_{2} / \mathrm{CTAB}$ Nanoskeleton and Hex-ncTiO $2 / \mathrm{CTAB} / \mathrm{COM}$ Nanoskeleton. Weight losses of the Hex-ncTiO $/$ CTAB Nanoskeleton, Hex-ncTiO $2 / \mathrm{CTAB} / \mathrm{C} 16 \mathrm{OH}$ Nanoskeleton, $\mathrm{Hex}-\mathrm{ncTiO}_{2} / \mathrm{CTAB} / \mathrm{C} 10$ Nanoskeleton and Hex-ncTiO $2 / \mathrm{CTAB} / \mathrm{TMB}$ Nanoskeleton during thermal treatment up to $600{ }^{\circ} \mathrm{C}$ measured by TG were $\sim 55 \%, \sim 53 \% \sim 35 \%$ and $\sim 31 \%$, respectively (see Figure 11), 
which were consistent with the thermal stability of the Hex-ncTiO $2 /$ CTAB Nanoskeleton and $\mathrm{Hex}-\mathrm{ncTiO}_{2} / \mathrm{CTAB} / \mathrm{COM}$ Nanoskeleton. Removal (decomposition) of the residual water, $\mathrm{CTAB}$ and $\mathrm{COM}$ would lead to collapsing the hexagonally pore-structure of Hex-ncTiO $2 /$ CTAB Nanoskeleton and Hex-ncTiO $2 /$ CTAB/COM Nanoskeleton. In particular, the amount of residual CTAB seems to affect significantly the thermal stability of Hex-ncTiO $2 /$ CTAB Nanoskeleton and $\mathrm{Hex}-\mathrm{ncTiO}_{2} / \mathrm{CTAB} / \mathrm{COM}$ Nanoskeleton. A exothermic process and weight loss attributing to the CTAB decomposition were observed in the temperature range of $200-350{ }^{\circ} \mathrm{C}$ in the $\mathrm{Hex}-\mathrm{ncTiO}{ }_{2} / \mathrm{CTAB}$ Nanoskeleton and Hex-ncTiO $2 / \mathrm{CTAB} / \mathrm{C} 16 \mathrm{OH}$ Nanoskeleton (see Figure 11a and b), while the process and weight loss were not observed in the case of $\mathrm{Hex}-\mathrm{ncTiO}_{2} / \mathrm{CTAB} / \mathrm{C} 10$ Nanoskeleton and Hex-ncTiO 2 /CTAB/TMB Nanoskeleton (see Figure 11c and d). This suggests that CTAB inside pores of the Hex-ncTiO $2 / \mathrm{CTAB} / \mathrm{C} 10$ Nanoskeleton and Hex-ncTiO $/$ /CTAB/TMB Nanoskeleton is removed during washing and drying processes. Namely, C10 and TMB help to remove $\mathrm{CTAB}$ inside pores. Also removal rate of the residual water, $\mathrm{CTAB}$ and $\mathrm{COM}$ in Hex-ncTiO $2 / \mathrm{CTAB}$ Nanoskeleton and $\mathrm{Hex}-\mathrm{ncTiO}_{2} / \mathrm{CTAB} / \mathrm{COM}$ Nanoskeleton should be related to the thermal stability of $\mathrm{Hex}-\mathrm{ncTiO}_{2} / \mathrm{CTAB}$ Nanoskeleton and Hex-ncTiO $2 / \mathrm{CTAB} / \mathrm{COM}$ Nanoskeleton. For example, the different thermal stability between $\mathrm{Hex}-\mathrm{ncTiO}{ }_{2} / \mathrm{CTAB}$ Nanoskeleton and $\mathrm{Hex}-\mathrm{ncTiO}_{2} / \mathrm{CTAB} / \mathrm{C} 16 \mathrm{OH}$ Nanoskeleton could be explained in terms of the removal rate of residual water, CTAB and COM in Hex-ncTiO $2 /$ CTAB Nanoskeleton and $\mathrm{Hex}-\mathrm{ncTiO}_{2} / \mathrm{CTAB} / \mathrm{C} 16 \mathrm{OH}$ Nanoskeleton (see Figure 11a and b). Weight loss of the Hex-nc $\mathrm{TiO}_{2} / \mathrm{CTAB}$ Nanoskeleton occurred gradually from $\sim 220{ }^{\circ} \mathrm{C}$ to $600{ }^{\circ} \mathrm{C}$, while weight loss of the $\mathrm{Hex}-\mathrm{ncTiO}_{2} / \mathrm{CTAB} / \mathrm{C} 16 \mathrm{OH}$ Nanoskeleton occurred dramatically from $\sim 220{ }^{\circ} \mathrm{C}$ to $400{ }^{\circ} \mathrm{C}$. This would be a reason why thermal stability of the $\mathrm{Hex}-\mathrm{ncTiO}_{2} / \mathrm{CTAB} / \mathrm{C} 16 \mathrm{OH}$ Nanoskeleton was lower than that of Hex-ncTiO 2 /CTAB Nanoskeleton. 
Overall, the thermal stability of $\mathrm{Hex}-\mathrm{ncTiO}_{2} / \mathrm{CTAB}$ Nanoskeleton and Hex-ncTiO $2 / \mathrm{CTAB} / \mathrm{COM}$ Nanoskeleton that we prepared were relatively high compared to the mesostructured titania materials reported.[10-22] This is most likely due to the non-crystallization and -crystal growth of the Hex-ncTiO $2 /$ CTAB Nanoskeleton and Hex-ncTiO $2 / \mathrm{CTAB} / \mathrm{COM}$ Nanoskeleton during thermal treatment. Wide-angle XRD patterns of Hex-ncTiO 2 /CTAB Nanoskeleton and Hex-ncTiO $/$ /CTAB/COM Nanoskeleton hardly changed in the temperature range of $150-450{ }^{\circ} \mathrm{C}$ (see Figure 12). Framework of the $\mathrm{Hex}_{-\mathrm{ncTiO}} / \mathrm{CTAB}$ Nanoskeleton and $\mathrm{Hex}-\mathrm{ncTiO}_{2} / \mathrm{CTAB} / \mathrm{COM}$ Nanoskeleton was crystallized during preparation process so that the framework would not be crystallized by calcination.

\subsection{Hex-ncTiO ${ }_{2} / \mathrm{CTAB} / \mathrm{COM}$ Nanoskeleton prepared using benzene (Bz), 1,3,5-triethylbenzene (TEB) and 1,3,5-triisopropylbenzene (TiPB)}

As mentioned in the sections 3.2 and 3.3, we found that TMB acts as an effective $\mathrm{COM}$ for pore-size expansion of the $\mathrm{Hex}-\mathrm{ncTiO}_{2} / \mathrm{CTAB} / \mathrm{COM}$ Nanoskeleton (see Figure 8) and enhances the thermal stability of the $\mathrm{Hex}-\mathrm{ncTiO}_{2} / \mathrm{CTAB} / \mathrm{COM}$ Nanoskeleton (see Figure 10 and Table 2). Then, we next examined benzene derivatives such as benzene (Bz), 1,3,5-triethylbenzene (TEB) and 1,3,5-triisopropylbenzene (TiPB) as COMs to obtain better insight on the COMs for pore-size expansion of the $\mathrm{Hex}-\mathrm{ncTiO}_{2} / \mathrm{CTAB} / \mathrm{COM}$ Nanoskeleton. These COMs allow us to evaluate the effect of molecular size of benzene derivative on the pore size of Hex-ncTiO $2 /$ CTAB/COM Nanoskeleton formed.

In the case of benzene $(\mathrm{Bz})$ that is smaller molecule than TMB molecule, no significant effect of benzene on the pore-size expansion of $\mathrm{Hex}-\mathrm{ncTiO}_{2} / \mathrm{CTAB} / \mathrm{Bz}$ Nanoskeleton was observed (see Figure 13). On the other hand, in the case of 1,3,5-triethylbenzene (TEB) that is larger molecule than TMB molecule, the maximum value of $d_{100}$-spacing estimated from the peak corresponding to (100) facet of 
Hex-ncTiO $2 / \mathrm{CTAB} / \mathrm{TEB}$ Nanoskeleton reached to $7.3 \mathrm{~nm}$ at $r_{\mathrm{TEB}}$ of 12 (see Figure 13). Average pore diameter and average framework thickness of Hex-ncTiO $/$ CTAB/TEB Nanoskeleton observed by TEM were $4.3 \mathrm{~nm}$ and $2.9 \mathrm{~nm}$ (see Figure 14), which was consistent with the value of $d_{100}$-spacing $(7.3 \mathrm{~nm})($ distance between pores $=$ pore diameter + framework thickness) estimated from low-angle XRD (see Table 1). Namely, pore size of the Hex-ncTiO 2 /CTAB/TEB Nanoskeleton became larger than that of Hex-ncTiO $2 / \mathrm{CTAB} / \mathrm{TMB}$ Nanoskeleton. However, in the case of TiPB which is largest molecule that we applied in this experiment, the maximum value of the $d_{100}$-spacing of Hex-ncTiO $2 / \mathrm{CTAB} / \mathrm{TiPB}$ Nanoskeleton was $6.0 \mathrm{~nm}$ at $r_{\mathrm{TiPB}}$ of 2 . These indicate that there is an appropriate molecular size for pore-size expansion of $\mathrm{Hex}-\mathrm{ncTiO}_{2} / \mathrm{CTAB} / \mathrm{COM}$ Nanoskeleton. This is most likely related to the competition between $\pi-\pi$ stacking of benzene derivatives in a $\mathrm{CTAB}$ micelle and their steric hindrance depending on molecular size. Here we also observed the limited pore-size $\left(d_{100}\right.$-spacing $)$ expansion of Hex-ncTiO $2 / \mathrm{CTAB} / \mathrm{COM}$ Nanoskeleton (see Figure 13). As discussed in section 3.2, this is most likely due to the contribution of CTAB-stabilized COM-in-water emulsions.

\section{Conclusions}

We examined the pore-size expansion of hexagonal-structured assembly of nanocrystalline titania (anatase) combined with $\mathrm{CTAB}$ (Hex-ncTiO $2 / \mathrm{CTAB}$ Nanoskeleton) using cosolvent organic molecules (COMs). In particular, the effects of COM solubilization site in a CTAB micelles and COM molecular size on the pore-size expansion of the Hex-ncTiO $2 / \mathrm{CTAB} / \mathrm{COM}$ Nanoskeleton were examined using various COMs such as 1-hexadecanol $(\mathrm{C} 16 \mathrm{OH})$, n-decane $(\mathrm{C} 10)$, benzene $(\mathrm{Bz})$, 1,3,5-trimethylbenzene (TMB), 1,3,5-triethylbenzene (TEB) and 1,3,5-triisopropylbenzene (TiPB). We revealed that every COMs that we examined in this work aided to enlarge pore size of the Hex-ncTiO $2 / \mathrm{CTAB} / \mathrm{COM}$ Nanoskeleton, while pore diameter of the Hex-ncTiO $/$ CTAB 
Nanoskeleton was $2.9 \mathrm{~nm}$ (the maximum $d_{100}$-spacing (distance between pores) of $4.1 \mathrm{~nm}$ ). Especially, TMB and TEB acted as effective COMs for pore-size expansion of Hex-ncTiO $2 / \mathrm{CTAB} / \mathrm{COM}$ Nanoskeleton. The maximum pore diameters observed by TEM (maximum $d_{100}$-spacing estimated from XRD) of the Hex-ncTiO 2 /CTAB/TMB Nanoskeleton Hex-ncTiO $2 / \mathrm{CTAB} / \mathrm{TEB}$ Nanoskeleton were $4.2 \mathrm{~nm}(6.8 \mathrm{~nm})$ and $4.3 \mathrm{~nm}(7.3 \mathrm{~nm})$, respectively. Furthermore, we revealed that thermal stability of the Hex-ncTiO $2 / \mathrm{CTAB} / \mathrm{TMB}$ Nanoskeleton became higher than that of Hex-ncTiO $/$ CTAB Nanoskeleton.

We believe that our findings reported here provide better insight on the pore-size expansion of mesostructured titania materials using cosolvent organic molecules (COMs) and the thermal stability of the mesostructured titania materials. Solubilization site of COM in a surfactant micelle and the resulting amount of COM solubilizing into surfactant micelles are related to the interaction between COM and surfactant, molecular size and geometrical structure. Thus, judicious selection of inorganic precursors, cosolvent organic molecules and amphiphilic molecules as templates and/or structure-directing agents should enable to tune the ordered pore-structure, pore size and thermal stability of mesostructured titania materials.

\section{Acknowledgment}

We are grateful to the Japan Aerospace Exploration Agency (Grant JDX-2005185A) for support of this research. 


\section{References}

[1] B. O'Regan, M. Gratzel, A low-cost, high-efficiency solar cell based on dye-sensitized colloidal titanium dioxide films, Nature 353 (1991) 737-740.

[2] M.K. Nazeeruddin, A. Kay, I. Rodicio, R. Humphry-Baker, E. Muller, P. Liska, N.

Vlachopoulos, M. Gratzel, Conversion of light to electricity by cis- $\mathrm{X}_{2}$ bis(2,2'-bipyridyl-4,4'-dicarboxylate)ruthenium(II) charge-transfer sensitizers $\left(\mathrm{X}=\mathrm{Cl}^{-}\right.$, $\mathrm{Br}^{-}, \mathrm{I}^{-}, \mathrm{CN}^{-}$, and $\mathrm{SCN}^{-}$) on nanocrystalline titanium dioxide electrodes, J. Am. Chem. Soc. 115 (1993) 6382-6390.

[3] M.R. Hoffmann, S.T. Martin, W. Choi, D.W. Bahnemann, Environmental applications of semiconductor photocatalysis, Chem. Rev. 115 (1995) 69-96.

[4] A. Hagfeldt, M. Gratzel, Light-induced redox reactions in nanocrystalline systems, Chem. Rev. 95 (1995) 49-68.

[5] A. Corma, From microporous to mesoporous molecular sieve materials and their use in catalysis, Chem. Rev. 97 (1997) 2373-2420.

[6] M. Gratzel, Mesoporous oxide junctions and nanostructured solar cells, Curr. Opin. Colloid Interf. Sci. 4 (1999) 314-321.

[7] A. Fujishima, X. Zhang, D.A. Tryk, Heterogeneous photocatalysis: From water photolysis to applications in environmental cleanup, Inter. J. Hydrogen Energy 32 (2007) $2664-2672$

[8] A. Fujishima, X.T. Zhang, D.A. Tryk, $\mathrm{TiO}_{2}$ photocatalysis and related surface phenomena, Surface Science Reports 63 (2008) 515-582.

[9] J.Y. Ying, C.P. Mehnert, M.S. Wong, Synthesis and applications of supramolecular-templated mesoporous materials, Angew. Chem. Int. Ed. 38 (1999) 56-77.

[10] P. Yang, D. Zhao, D.I. Margolese, B.F. Chmelka, G.D. Stucky, Block copolymer templating syntheses of mesoporous metal oxides with large ordering lengths and 
semicrystalline framework, Chem. Mater. 11 (1999) 2813-2826.

[11] G.J.d.A.A. Soler-Illia, A. Louis, C. Sanchez, Synthesis and characterization of mesostructured titania-based materials through evaporation-induced self-assembly, Chem. Mater. 14 (2002) 750-759.

[12] E.L. Crepaldi, G.J.D.A. Soler-Illia, D. Grosso, M. Sanchez, Nanocrystallised titania and zirconia mesoporous thin films exhibiting enhanced thermal stability, New J. Chem. 27 (2003) 9-13.

[13] E.L. Crepaldi, G.J.D.A. Soler-Illia, D. Grosso, F. Cagnol, F. Ribot, C. Sanchez, Controlled formation of highly organized mesoporous titania thin films: From mesostructured hybrids to mesoporous nanoanatase $\mathrm{TiO}_{2}$, J. Am. Chem. Soc. 125 (2003) 9770-9786.

[14] K. Cassiers, T. Linssen, M. Mathieu, Y.Q. Bai, H.Y. Zhu, P. Cool, E.F. Vansant, Surfactant-directed synthesis of mesoporous titania with nanocrystalline anatase walls and remarkable thermal stability, J. Phys. Chem. B 108 (2004) 3713-3721.

[15] K.S. Liu, M.L. Zhang, K.Y. Shi, H.G. Fu, Large-pore mesoporous nanocrystalline titania thin films synthesized through evaporation-induced self-assembly, Mater. Lett. 59 (2005) 3308-3310.

[16] K.S. Liu, H.G. Fu, K.Y. Shi, F.S. Xiao, L.Q. Jing, B.F. Xin, Preparation of large-pore mesoporous nanocrystalline $\mathrm{TiO}_{2}$ thin films with tailored pore diameters, J. Phys. Chem. B 109 (2005) 18719-18722.

[17] T. Sreethawong, Y. Suzuki, S. Yoshikawa, Synthesis, characterization, and photocatalytic activity for hydrogen evolution of nanocrystalline mesoporous titania prepared by surfactant-assisted templating sol-gel process, J. Solid State Chem. 178 (2005) 329-338.

[18] M. Cecilia Fuertes, G.J.A.A. Soler-Illia, Processing of macroporous titania thin films: From multiscale functional porosity to nanocrystalline macroporous $\mathrm{TiO}_{2}$, Chem. Mater. 18 (2006) 2109-2117.

[19] M M. Zukalova, A. Zukal, L. Kavan, M.K. Nazeeruddin, P. Liska, M. Gratzel, 
Organized mesoporous $\mathrm{TiO}_{2}$ films exhibiting greatly enhanced performance in dye-sensitized solar cells, Nano Lett. 5 (2005) 1789-1792.

[20] S.Y. Choi, M. Mamak, N. Coombs, N. Chopra, G.A. Ozin, Thermally stable two-dimensional hexagonal mesoporous nanocrystalline anatase, meso-nc- $\mathrm{TiO}_{2}$ : Bulk and crack-free thin film morphologies, Adv. Funct. Mater. 14 (2004) 335-344.

B. Chi, L. Zhao, J. Li, J. Pu, Y. Chen, C.C. Wu, T. Jin, $\mathrm{TiO}_{2}$ mesoporous thick films with large-pore structure for dye-sensitized solar cell, J. Nanosci. Nanotechnol. 8 (2008) $3877-3882$.

[22] V. Meynen, P. Cool, E.F. Vansant, Verified syntheses of mesoporous materials, Micropor. Mesopor. Mater. 125 (2009) 170-223.

[23] J.S. Beck, J.C. Vartuli, W.J. Roth, M.E. Leonowicz, C.T. Kresge, K.D. Shmitt, C.T.-W. Chu, D.H. Olsen, E.W. Sheppard, S.B. McCullen, J.B. Higgins, J.L. Schlenker, A New family of mesoporous molecular sieves prepared with liquid crystal templates, J. Am. Chem. Soc. 114 (1992) 10834-10843.

[24] J.L. Blin, C. Otjacques, G. Herrier, B.-L. Su, Pore size engineering of mesoporous silicas using decane as expander, Langmuir 16 (2000) 4229-4236.

[25] D. Zhao, J. Feng, Q. Huo, N. Melosh, G.H. Fredrickson, B.F. Chmelka, G.D. Stucky, Triblock copolymer syntheses of mesoporous silica with periodic 50 to 300 angstrom pores, Science 279 (1998) 548-552.

[26] N. Ulagappan, C.N.R. Rao, Evidence for supramolecular organization of alkane and surfactant molecules in the process of forming mesoporous silica, Chem. Commun. (1996) 2759-2760.

B. Lefevre, A. Galarneau, J. Lapichella, C. Petitto, F. Di Renzo, F. Fajula, Z. Bayram-Hahn, R. Skudas, K. Unger, Synthesis of large-pore mesostructured micelle-templated silicas as discrete spheres, Chem. Mater. 17 (2005) 601-607.

[28] A.M. Lapena, A.F. Gross, S.H. Tolbert, Examining the role of surfactant packing in 
phase transformations of periodic templated silica/surfactant composites, Langmuir 21 (2005) $470-480$.

[29] T.-W. Kim, F. Kleitz, B. Paul, R. Ryoo, MCM-48-like large mesoporous silicas with tailored pore structure: Facile synthesis domain in a ternary triblock copolymer-butanol-water system, J. Am. Chem. Soc. 127 (2005) 7601-7610.

[30] H. Shibata, T. Ogura, T. Mukai, T. Ohkubo, H. Sakai, M. Abe, Direct synthesis of mesoporous titania particles having a crystalline wall, J. Am. Chem. Soc. 127 (2005) 16396-16397.

[31] H. Shibata, H. Mihara, T. Mukai, T. Ogura, H. Kohno, T. Ohkubo, H. Sakai, M. Abe, Preparation and formation mechanism of mesoporous titania particles having crystalline wall, Chem. Mater. 18 (2006) 2256-2260.

[32] T. Sakai, H. Yano, M. Ohno, H. Shibata, K. Torigoe, S. Utsumi, K. Sakamoto, N. Koshikawa, S. Adachi, H. Sakai, M. Abe, Formation mechanism for hexagonal-structured self-assemblies of crystalline titania templated by cetyltrymethylammonium bromide, J. Oleo Sci. 57 (2008) 629-637.

[33] T. Sakai, M. Ohno, H. Yano, H. Shibata, K. Totigoe, S. Utsumi, K. Sakaimoto, N. Koshikawa, S. Adachi, H. Sakai, M. Abe, Cethyltrimethylammonium bromide-mediated hexagonal-structured self-assembly of nanocrystalline titania: Gravity effect on framework formation and crystal growth", J. Jpn. Soc. Microgravity Appl. 26 (2009) 2-8.

[34] J.C. Eriksson, G. Gillberg, N.M.R. studies of the solubilization of aromatic compounds in cetyltrimethylammonium bromide solution. II, Acta Chemica Scandinavica 20 (1966) 2019-2027.

[35] H. Kunieda, K. Ozawa, K.L. Huang, Effect of oil on the surfactant molecular curvatures in liquid crystals, J. Phys. Chem. B 102 (1998) 831-838.

[36] H.P. Klug, L.E. Alexander, X-Ray Diffraction Procedures For Polycrystalline and Amorphous Materials, John Wiley \& Sons, Inc., New York, 1974. 
COLSUA-D-10-00611 Revised August 2010

[37] H. Zhang, J.F. Banfield, Kinetics of crystallization and crystal growth of nanocrystalline anatase in nanometer-sized amorphous titania, Chem. Mater. 14 (2002) 4145-4154. 
Table 1. Pore diameters and framework thicknesses observed by TEM and maximum values of $d_{100}$-spacing of Hex-ncTiO $/$ CTAB Nanoskeleton and $\mathrm{Hex}-\mathrm{ncTiO}_{2} / \mathrm{CTAB} / \mathrm{COM}$ Nanoskeleton

\begin{tabular}{|c|c|c|c|}
\hline \multirow[b]{2}{*}{ Sample } & \multicolumn{2}{|c|}{ TEM } & XRD \\
\hline & $\begin{array}{l}\text { Average pore } \\
\text { diameter / nm }\end{array}$ & $\begin{array}{c}\text { Average framework } \\
\text { thickness / nm }\end{array}$ & $\begin{array}{l}\text { Average maximum } \\
d_{100 \text {-spacing / } \mathrm{nm}}\end{array}$ \\
\hline $\begin{array}{c}\text { Hex-ncTiO } 2 / \text { CTAB } \\
\text { Nanoskeleton }\end{array}$ & 2.9 & 1.2 & 4.1 \\
\hline 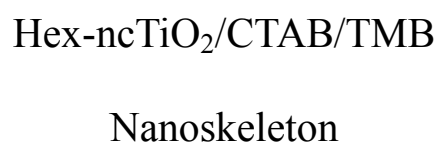 & 4.2 & 2.7 & 6.8 \\
\hline $\begin{array}{c}\text { Hex-ncTiO } 2 / C T A B / T E B \\
\text { Nanoskeleton }\end{array}$ & 4.3 & 2.9 & 7.3 \\
\hline
\end{tabular}


COLSUA-D-10-00611 Revised August 2010

Table 2. Highest temperatures that XRD peak corresponding to (100) facet of hexagonally

\begin{tabular}{|c|c|c|}
\hline Sample & $\begin{array}{l}\text { Average maximum } \\
d_{100} \text {-spacing / } \mathrm{nm}\end{array}$ & Temperature $/{ }^{\circ} \mathrm{C}$ \\
\hline $\mathrm{Hex} \mathrm{ncTiO}_{2} / \mathrm{CTAB}$ Nanoskeleton & 4.1 & 300 \\
\hline $\begin{array}{c}\text { Hex-ncTiO } / \text { CTAB/C16OH } \\
\text { Nanoskeleton }\end{array}$ & 4.9 & 200 \\
\hline $\begin{array}{c}\text { Hex-ncTiO } 2 / \mathrm{CTAB} / \mathrm{C} 10 \\
\text { Nanoskeleton }\end{array}$ & 5.8 & 400 \\
\hline $\begin{array}{c}\text { Hex-ncTiO } 2 / \mathrm{CTAB} / \mathrm{TMB} \\
\text { Nanoskeleton }\end{array}$ & 6.8 & 400 \\
\hline
\end{tabular}




\section{Figure captions}

Figure 1. Schematic of proposed mechanism on $\mathrm{Hex}-\mathrm{ncTiO}_{2} / \mathrm{CTAB} / \mathrm{COM}$ Nanoskeleton formation using COM-swollen CTAB micelles.

Figure 2. Temperature profile for calcination of $\mathrm{Hex}-\mathrm{ncTiO} \mathrm{Ti}_{2} / \mathrm{CTAB}$ Nanoskeleton and Hex-ncTiO $2 /$ CTAB/COM Nanoskeleton.

Figure 3. Low-angle (upper panel) and wide-angle (bottom panel) XRD patterns of Hex-ncTiO $2 /$ CTAB Nanoskeleton.

Figure 4. TEM images of Hex-ncTiO 2 /CTAB Nanoskeleton.

Figure 5. Low-angle (upper panel) and wide-angle XRD (bottom panel) patterns of Hex-ncTiO $2 / \mathrm{CTAB} / \mathrm{C} 16 \mathrm{OH}$ Nanoskeleton prepared at different $\mathrm{C} 16 \mathrm{OH} / \mathrm{CTAB}$ mixing ratios $\left(r_{\mathrm{C} 16 \mathrm{OH}}=0-1\right)$. Opened triangle $(\nabla)$ in bottom panel points a peak assigned to 1-hexadecanol.

Figure 6. Low-angle (upper panel) and wide-angle XRD (bottom panel) patterns of Hex-ncTiO $2 / \mathrm{CTAB} / \mathrm{C} 10$ Nanoskeleton prepared at different $\mathrm{C} 10 / \mathrm{CTAB}$ mixing ratios $\left(r_{\mathrm{C} 10}=\right.$ $0-25)$.

Figure 7. Low-angle (bottom panel) and wide-angle (bottom panel) XRD patterns of Hex-ncTiO ${ }_{2} / \mathrm{CTAB} / \mathrm{TMB}$ Nanoskeleton prepared at different TMB/CTAB mixing ratios $\left(r_{\mathrm{TMB}}\right.$ $=0-20)$.

Figure 8. Values of $d_{100}$-specing plotted as a function of COM/CTAB molar ratio $\left(r_{\mathrm{COM}}\right)$. COM: $\mathrm{C} 16 \mathrm{OH}(\bullet), \mathrm{C} 10(\square)$ and TMB (ø). Bar represents minimum and maximum values of $d_{100}$-specing that we measured.

Figure 9. TEM images of Hex-ncTiO $2 / \mathrm{CTAB} / \mathrm{TMB}$ Nanoskeleton prepared at TMB/CTAB molar ratio of $16\left(r_{\mathrm{TMB}}=16\right)$.

Figure 10. Low-angle XRD patterns of (a) Hex-ncTiO ${ }_{2} / \mathrm{CTAB}$ Nanoskeleton, (b) Hex-ncTiO ${ }_{2} / \mathrm{CTAB} / \mathrm{C} 16 \mathrm{OH}$ Nanoskeleton $\left(r_{\mathrm{C} 16 \mathrm{OH}}=1\right)$, (c) Hex-ncTiO $2 / \mathrm{CTAB} / \mathrm{C} 10$ Nanoskeleton $\left(r_{\mathrm{C} 10}=12\right)$ and $(\mathrm{d}) \mathrm{Hex}-\mathrm{ncTiO}_{2} / \mathrm{CTAB} / \mathrm{TMB}$ Nanoskeleton $\left(r_{\mathrm{TMB}}=16\right)$ calcined at various temperatures. Low-angle XRD patterns at $120{ }^{\circ} \mathrm{C}$ correspond to those of 
dried samples.

Figure 11. TG (solid line) and DSC (dashed line) curves of (a) Hex-ncTiO $2 / \mathrm{CTAB}$ Nanoskeleton, (b) Hex-ncTiO ${ }_{2} / \mathrm{CTAB} / \mathrm{C} 16 \mathrm{OH}$ Nanoskeleton $\left(r_{\mathrm{C} 16 \mathrm{OH}}=1\right)$, (c) Hex-ncTiO $2 / \mathrm{CTAB} / \mathrm{C} 10$ Nanoskeleton $\left(r_{\mathrm{C} 10}=12\right)$ and (d) Hex-ncTiO $2 / \mathrm{CTAB} / \mathrm{TMB}$ Nanoskeleton $\left(r_{\mathrm{TMB}}=16\right)$.

Figure 12. Wide-angle XRD patterns of (a) Hex-ncTiO $2 / C T A B$ Nanoskeleton, (b) Hex-ncTiO ${ }_{2} / \mathrm{CTAB} / \mathrm{C} 16 \mathrm{OH}$ Nanoskeleton $\left(r_{\mathrm{C} 16 \mathrm{OH}}=1\right)$, (c) Hex-ncTiO $2 / \mathrm{CTAB} / \mathrm{C} 10$ Nanoskeleton $\left(r_{\mathrm{C} 10}=12\right)$ and $(\mathrm{d}) \mathrm{Hex}-\mathrm{ncTiO}_{2} / \mathrm{CTAB} / \mathrm{TMB}$ Nanoskeleton $\left(r_{\mathrm{TMB}}=16\right)$ calcined at various temperatures. Wide-angle XRD patterns at $120{ }^{\circ} \mathrm{C}$ correspond to those of dried samples.

Figure 13. Values of $d_{100}$-specing plotted as a function of COM/CTAB molar ratio $\left(r_{\mathrm{COM}}\right)$. COM: Bz $(\diamond)$, TMB $(\boldsymbol{\square})$, TEB $(\boldsymbol{\Delta})$ and TiPB $(\circ)$. Bar represents minimum and maximum values of $d_{100}$-specing that we measured.

Figure 14. TEM images of Hex-ncTiO $2 / \mathrm{CTAB} / \mathrm{TEB}$ Nanoskeleton prepared at TEB/CTAB molar ratio of $12\left(r_{\mathrm{TEB}}=12\right)$. 
Figure 1. Sakai et al.
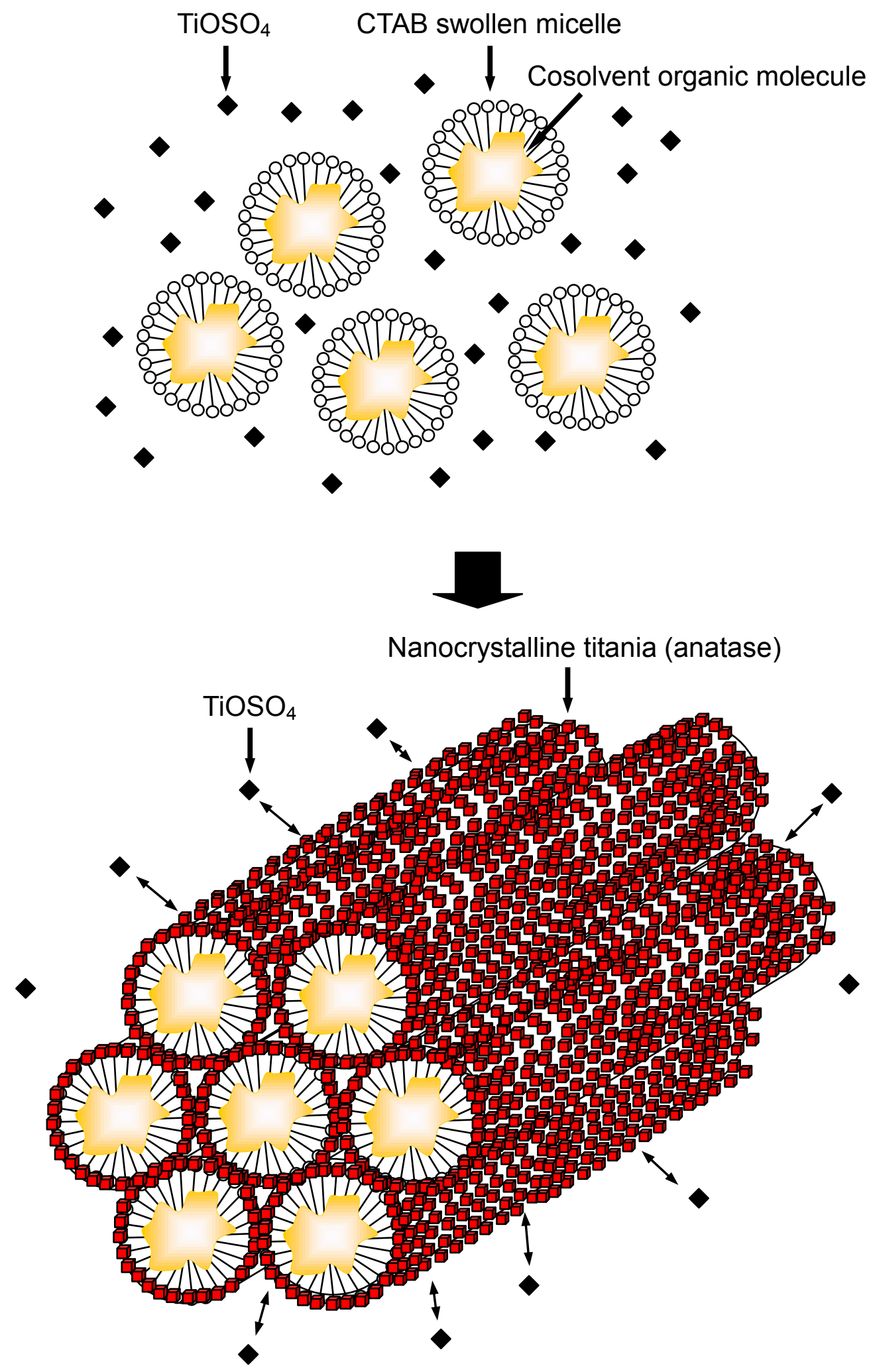
Figure 2. Sakai et al.

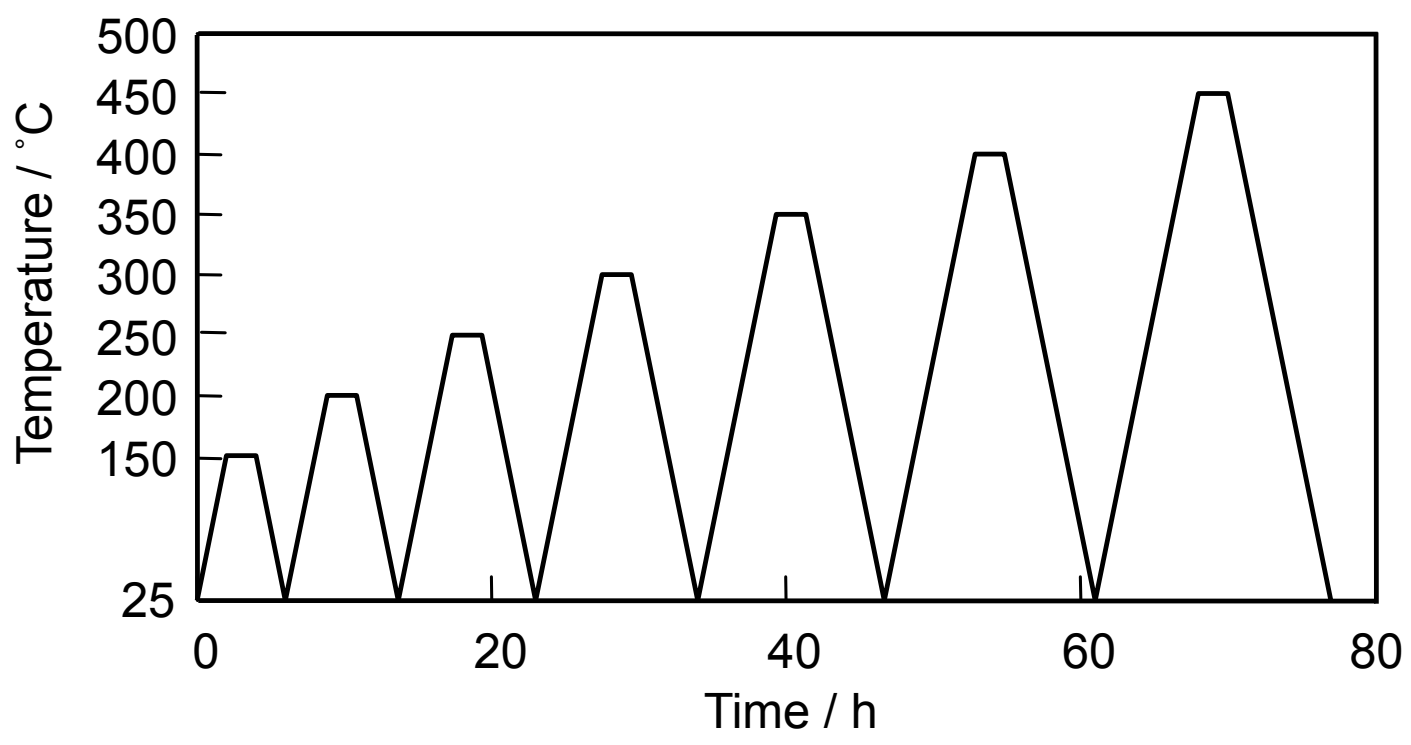


Figure 3. Sakai et al.
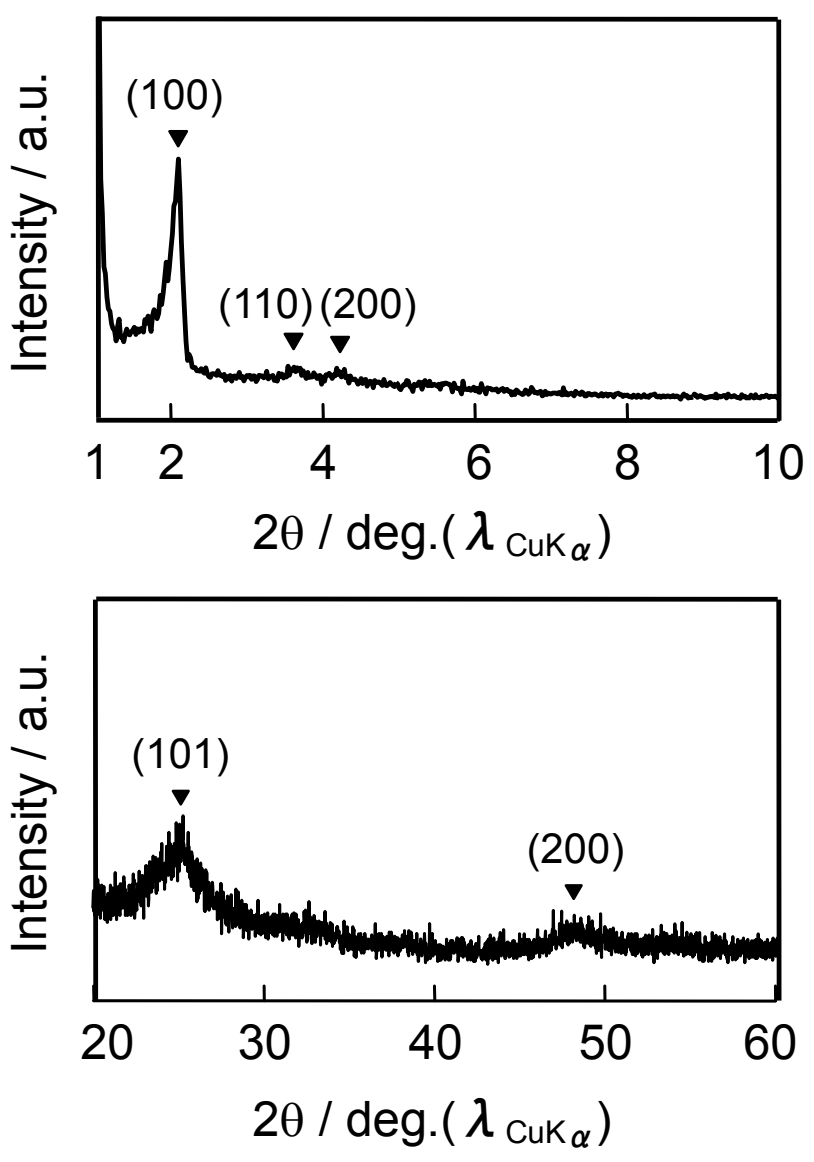
COLSUA-D-10-00611 Revised August 2010

Figure 4. Sakai et al.
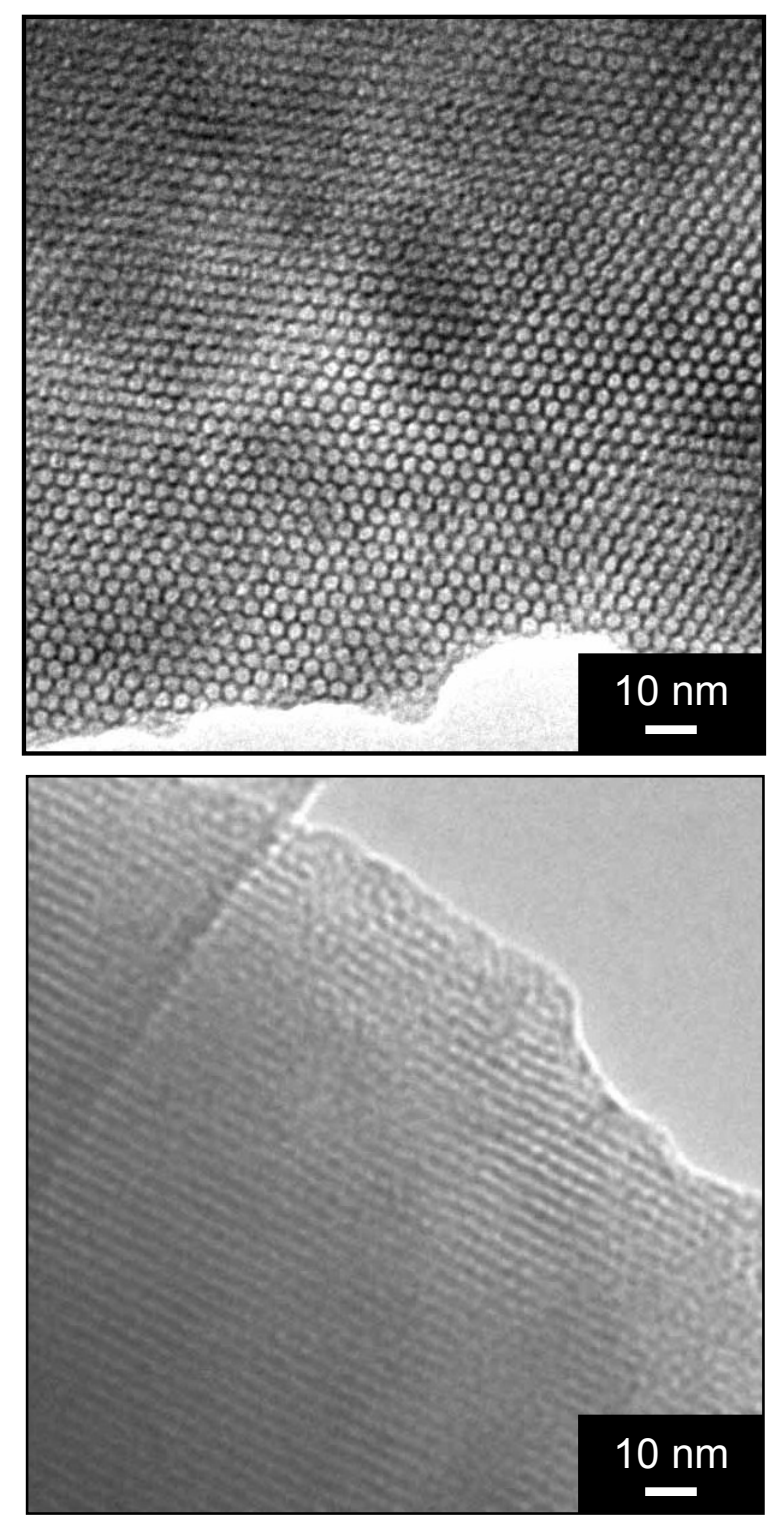
Figure 5. Sakai et al.
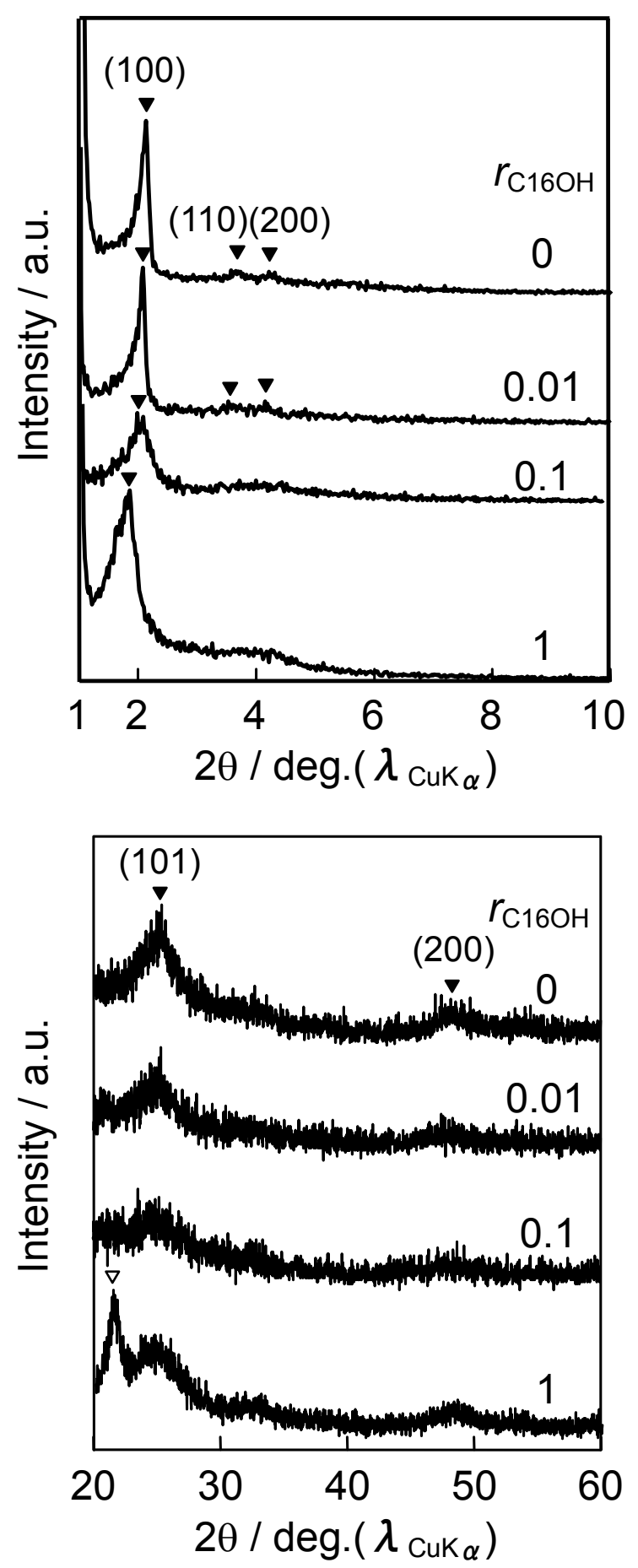
Figure 6. Sakai et al.
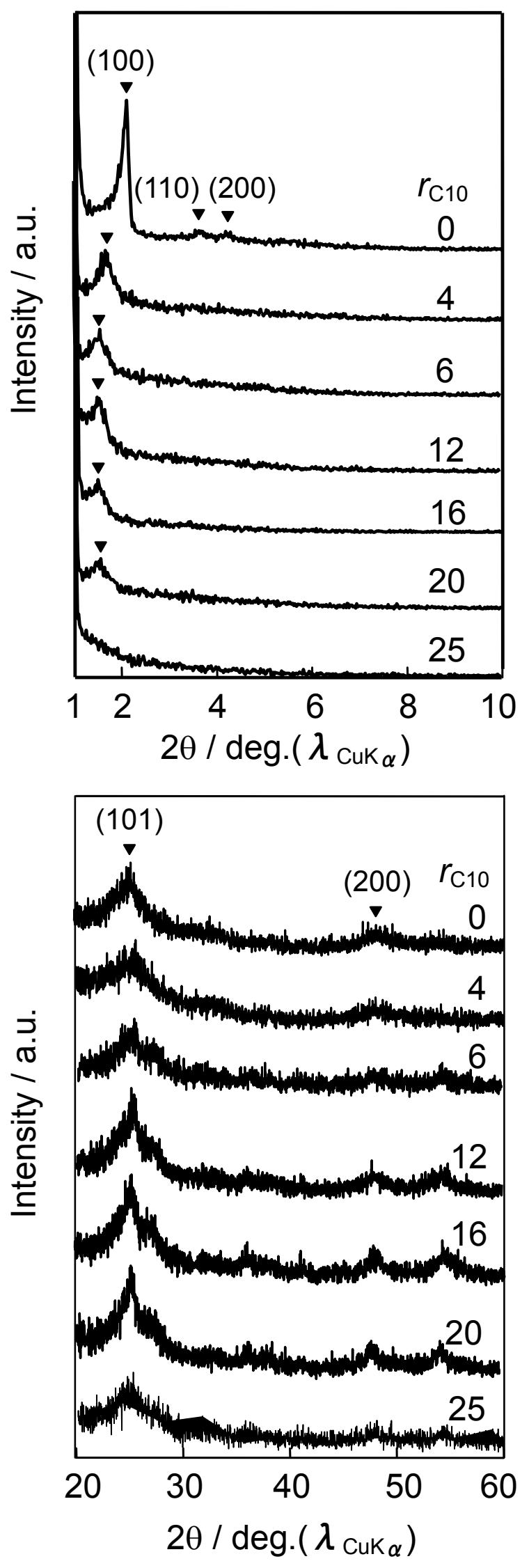
Figure 7. Sakai et al.
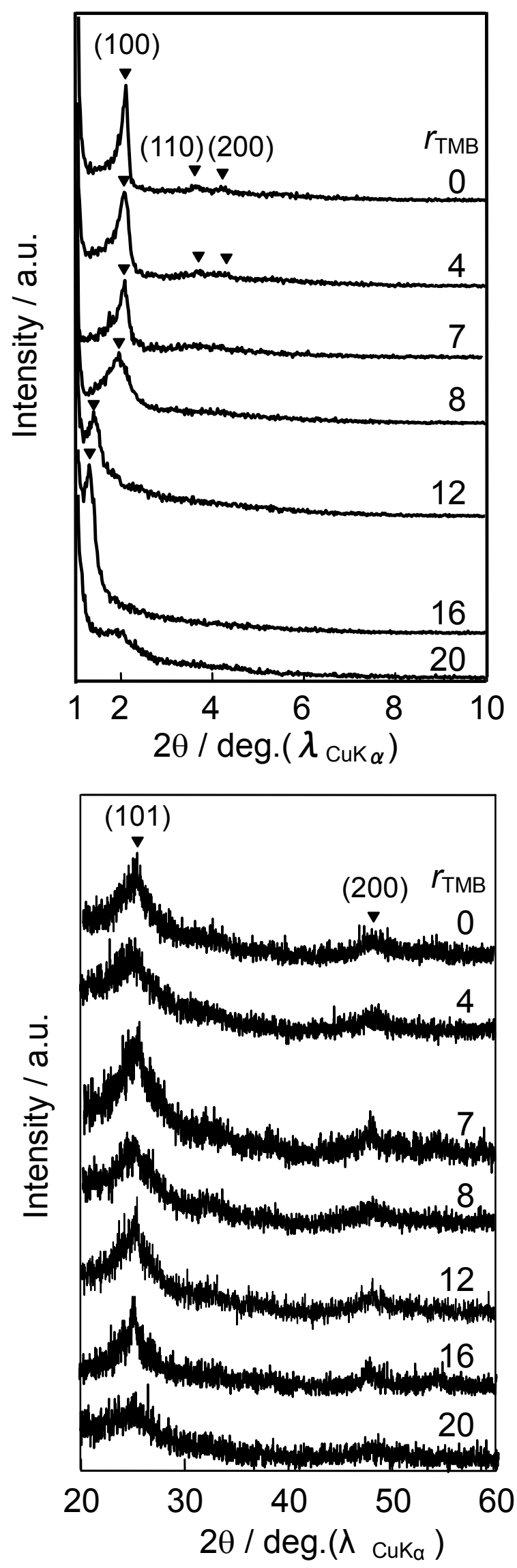
COLSUA-D-10-00611 Revised August 2010

Figure 8. Sakai et al.

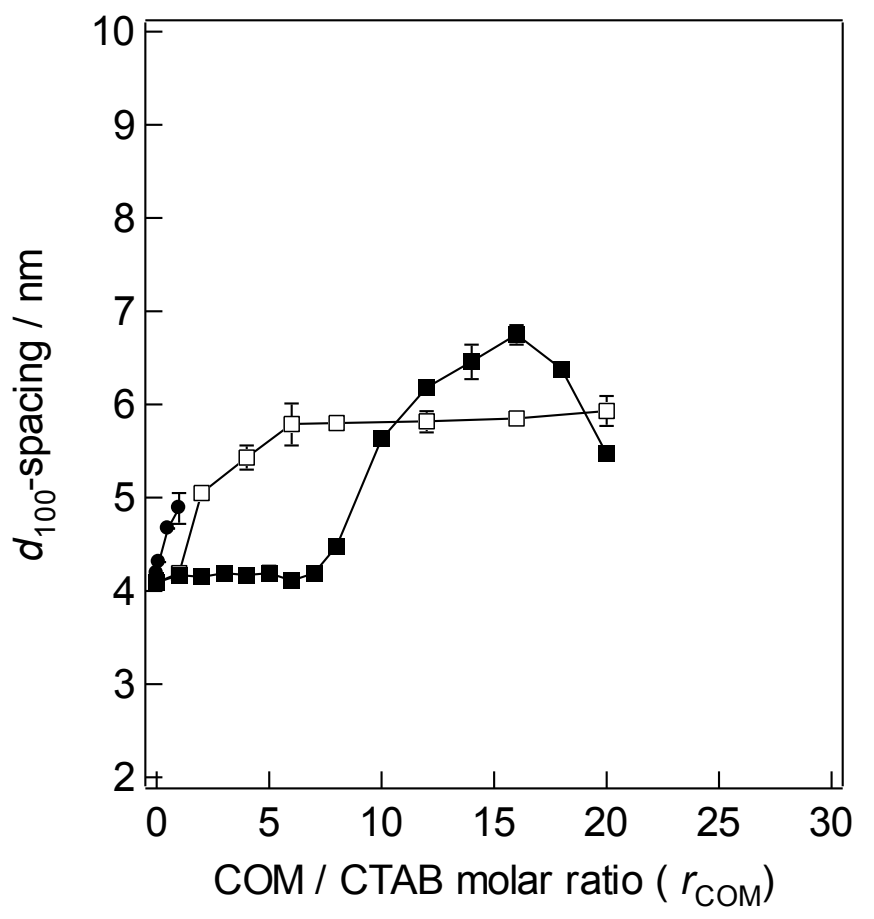


COLSUA-D-10-00611 Revised August 2010

Figure 9. Sakai et al.
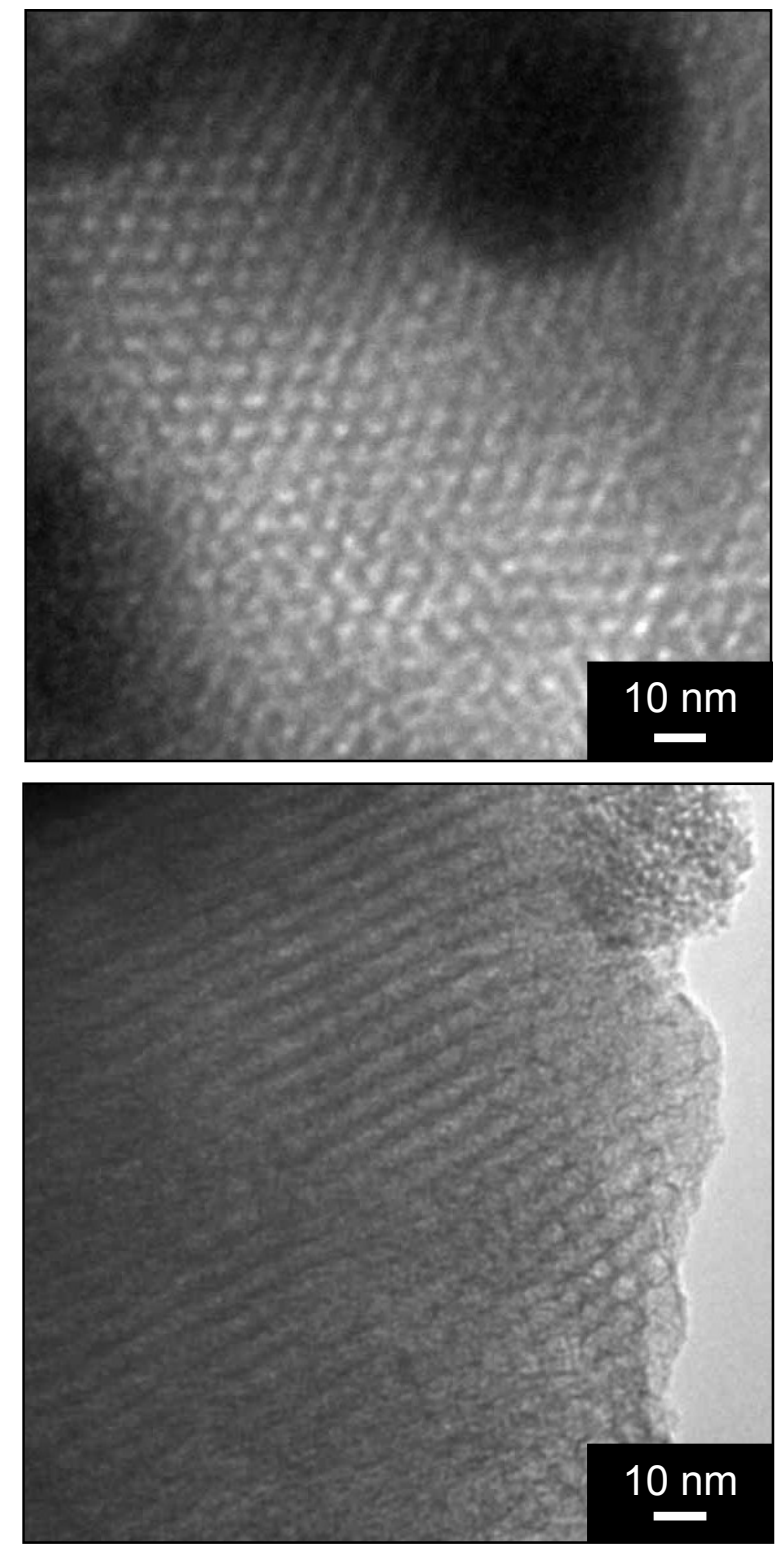
Figure 10. Sakai et al.
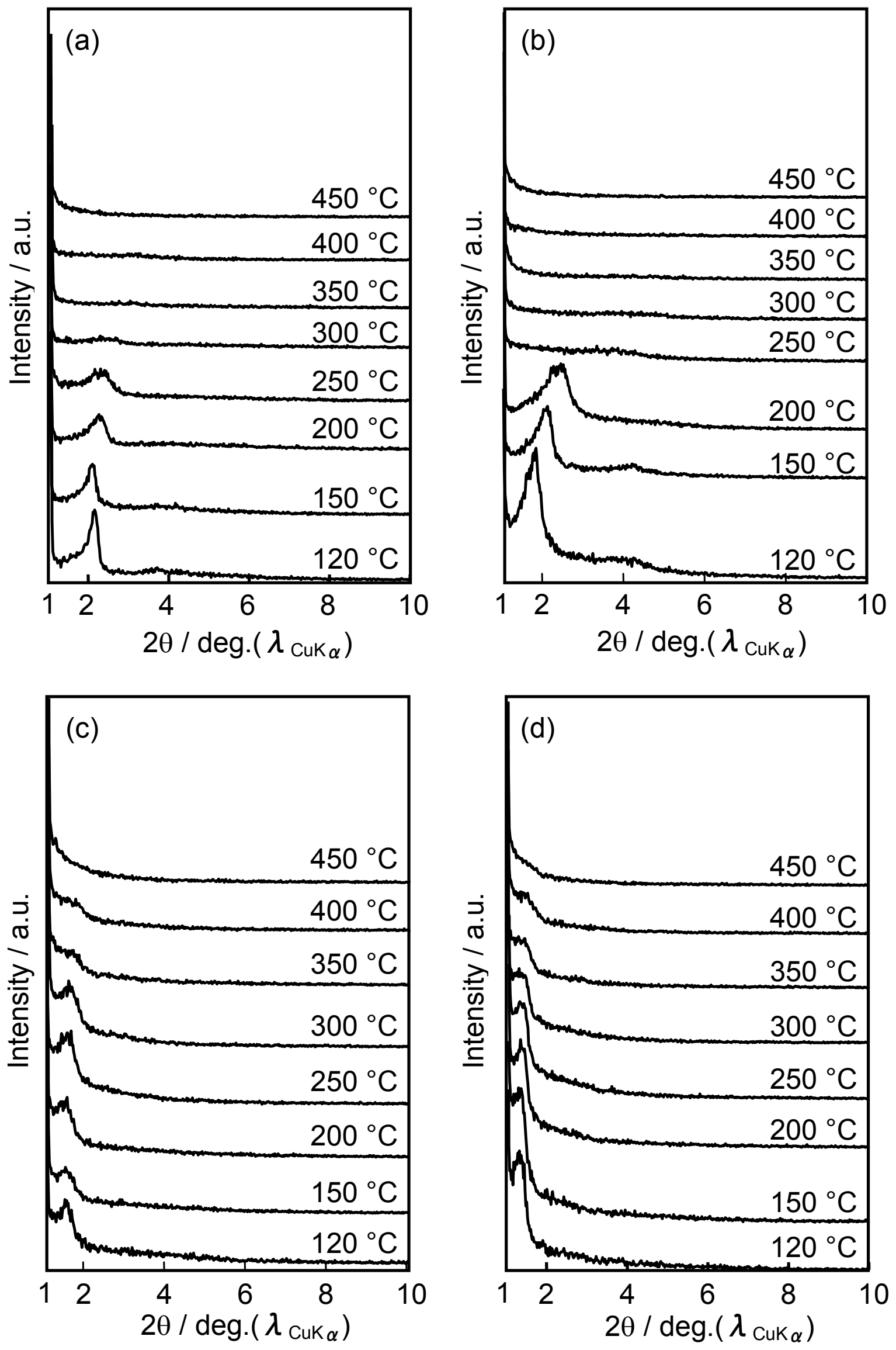
Figure 11. Sakai et al.
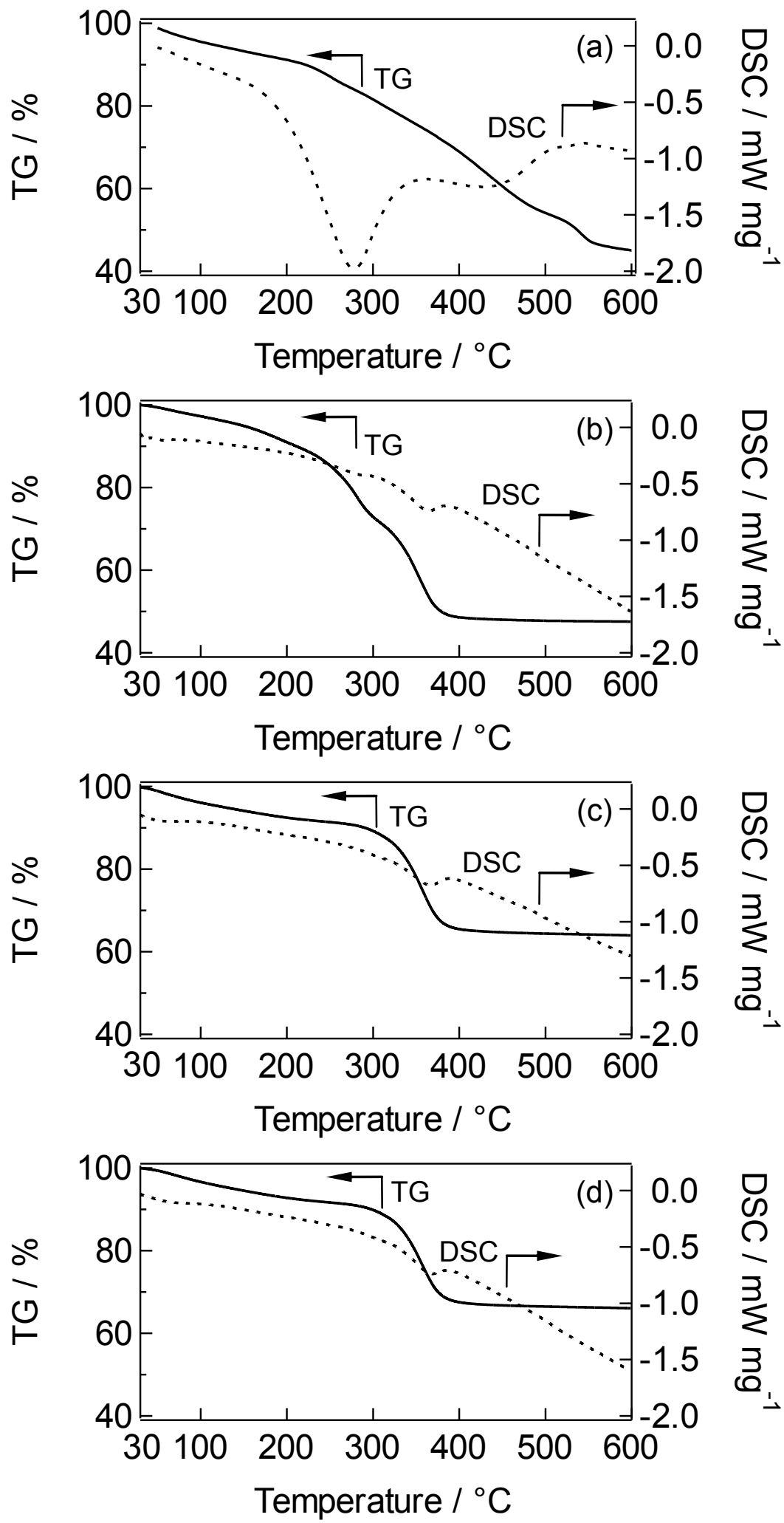
Figure 12. Sakai et al.
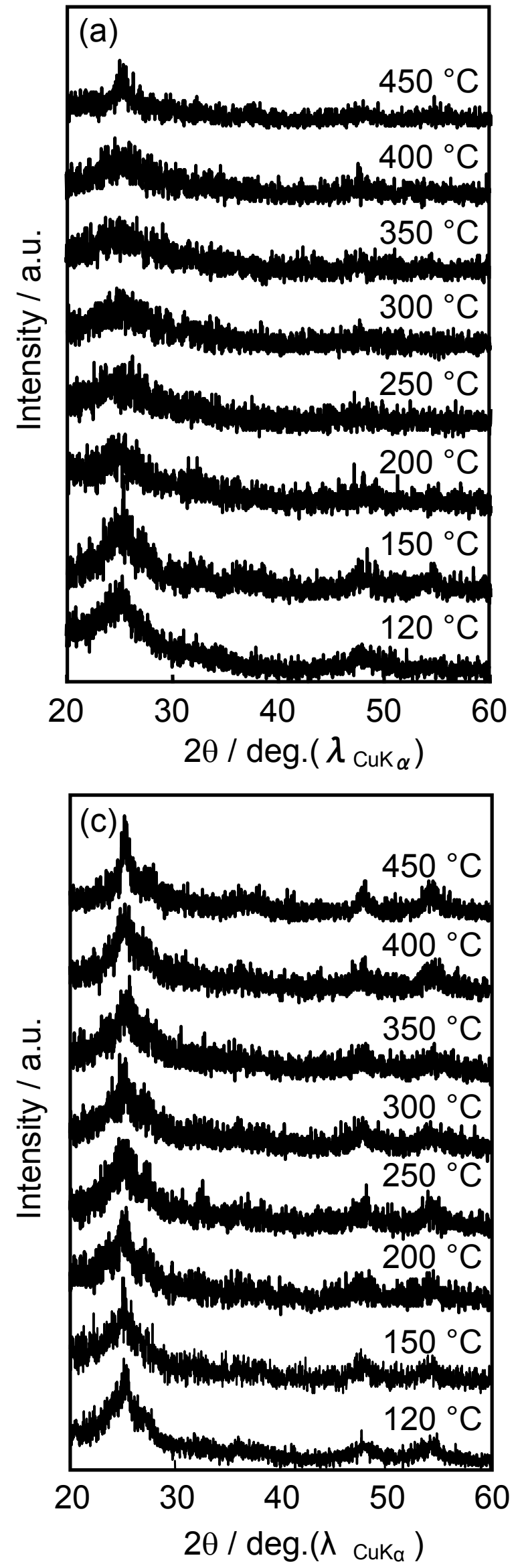
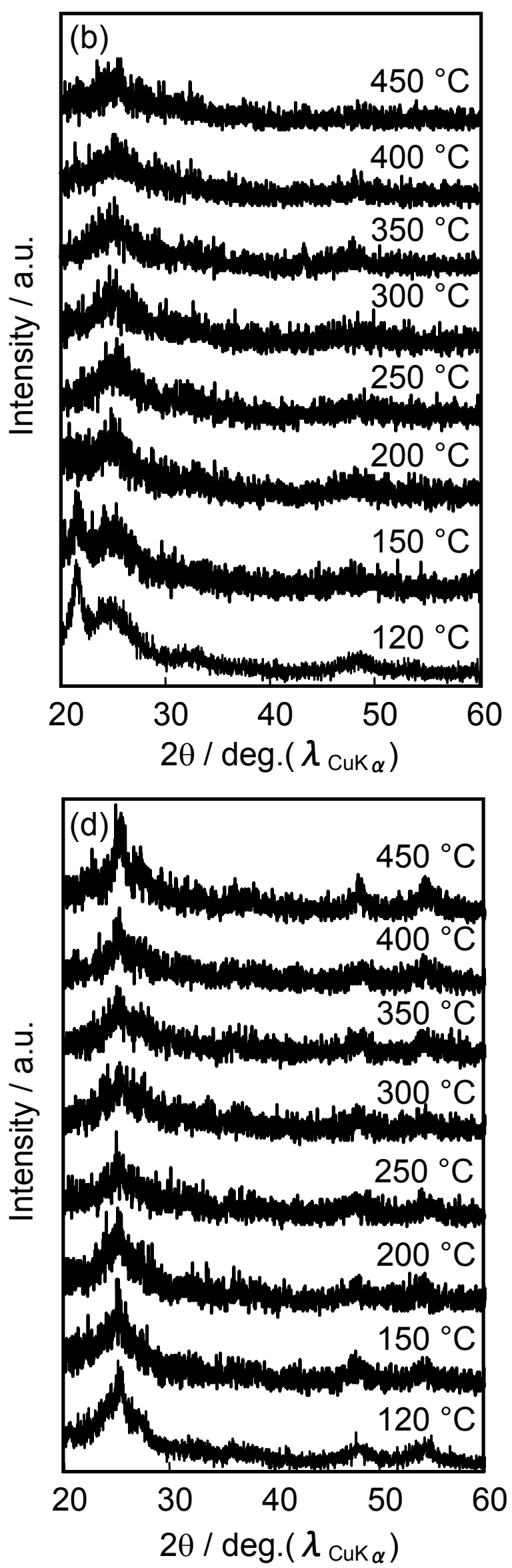
COLSUA-D-10-00611 Revised August 2010

Figure 13. Sakai et al.

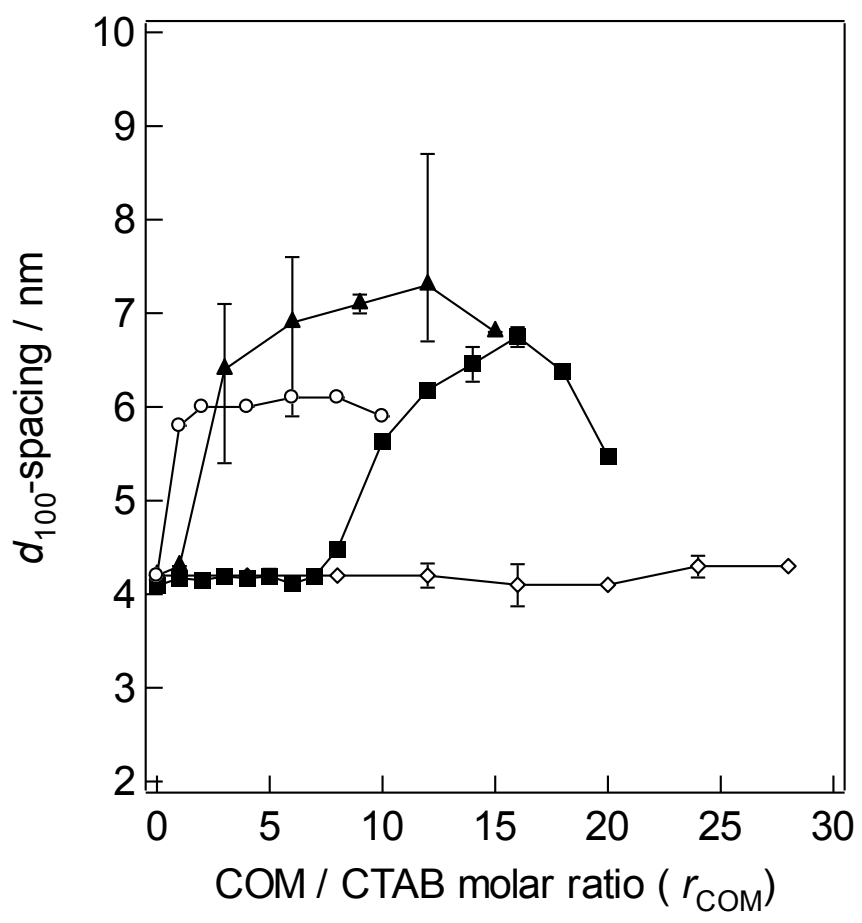


COLSUA-D-10-00611 Revised August 2010

Figure 14. Sakai et al.
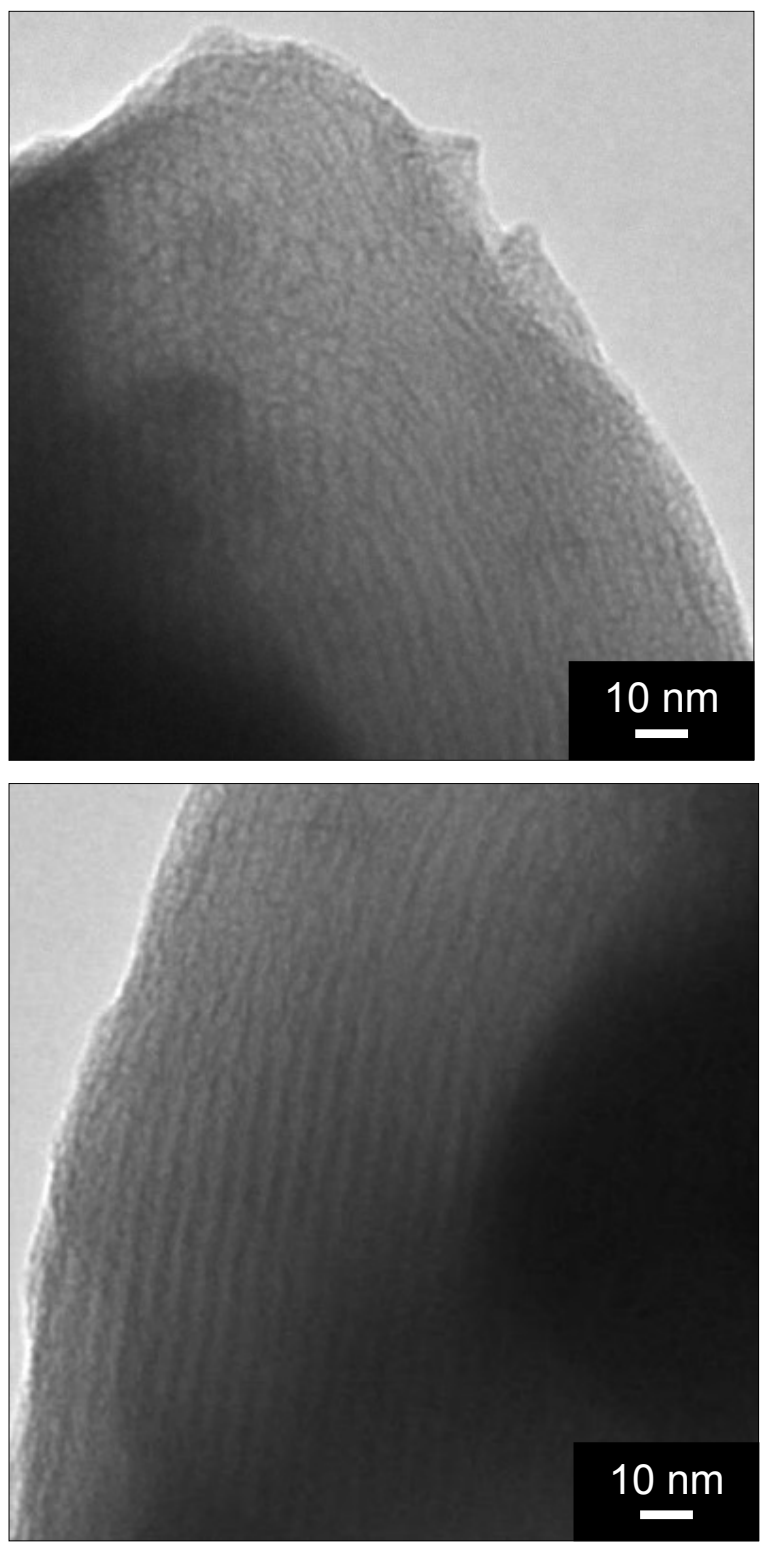